\title{
Immigration and the school system
}

\author{
Facundo Albornoz ${ }^{1,2}$ - Antonio Cabrales ${ }^{3}$. \\ Esther Hauk ${ }^{4}$
}

Received: 18 August 2016/ Accepted: 9 March 2017 / Published online: 27 March 2017 (C) The Author(s) 2017. This article is an open access publication

\begin{abstract}
This paper presents a tractable model to study the effect of immigration on host countries' school system and student outcomes. In our model, education quality and student outcomes are determined endogenously by the interaction of parents, schools and policy-makers deciding educational resources. Immigration decisions are based on economic factors, immigration policy, as well as on "parental motivation" (parents' concerns about their children education achievement). The model yields results that are consistent with central empirical regularities of the school effects of immigration: (1) there is a negative effect of immigrant pupils on native students;
\end{abstract}

We thank Paula Calvo for excellent research assistance. We thank Roberto Burguet, Jesus Fernández-Huertas Moraga, Héctor Calvo-Pardo, Omar Licandro, Paolo Giordani and seminar participants at the IAE, LUISS, Universidad de San Andrés, UB, University of Valencia, MOVE Workshop on Cultural Economics, INSIDE-MOVE, NORFACE, CReAM: VI Workshop on Migration and Labor Economics, NYU Abu Dhabi and CSEF Naples for valuable comments. Hauk acknowledges financial support from the Spanish Ministry of Economy and Competitiveness through the Severo Ochoa Program for Centers of Excellence in R\&D (SEV-2011-0075) and through CICYT project number ECO2012-37065 and from the government of Catalonia.

$凶 \quad$ Facundo Albornoz

facundo.albornoz@nottingham.ac.uk

Antonio Cabrales

a.cabrales@ucl.ac.uk

Esther Hauk

esther.hauk@iae.csic.es

1 School of Economics, University of Nottingham, Nottingham, UK

2 CONICET-IIEP, Buenos Aires, Argentina

3 Department of Economics, University College London, London, UK

4 Instituto de Análisis Económico (IAE-CSIC), Barcelona Graduate School of Economics, Campus $\mathrm{UAB}$, Bellaterra, Barcelona, Spain 
(2) the increasing shares of immigrant students are associated with the decline of school resources and quality; (3) the school performance of immigrant children is positively associated with immigration costs; and (4) school achievement increases in parental motivation and those immigrant children with highly motivated parents tend to outperform native children. Importantly, our analysis clarifies under which conditions these empirical regularities take place and emphasizes that the effect of immigration on native pupils is mediated by the way the school system reacts to changes in class composition.

Keywords Education · Immigration - School resources · Education quality · Parental involvement $\cdot$ Immigrant sorting

JEL Classification I20 $\cdot$ I21 $\cdot$ I28 $\cdot$ J24 $\cdot$ J61

\section{Introduction}

Immigration is a prevalent feature of many societies. Given that immigration involves families, the future of the host societies depends on how immigrant children perform at school and how their presence affects the school system. ${ }^{1}$ Clearly, the school success of immigrant children has a direct impact on human capital accumulation in the host country. But also, as immigrant children are to be schooled, they change classroom composition and school resources. Therefore, they might have a sizeable (not necessarily negative) impact on school quality and the performance of their native peers.

Logically, the educational effect of immigration is a core concern of policy-makers and has generated a lot of research effort, mainly empirical. ${ }^{2}$ Among the many findings of this literature, we concentrate on the following empirical regularities (for which we give precise references in a few paragraphs) which are very important for the public discussion: there is a negative effect of immigrant pupils on native students (empirical regularity 1); the increasing shares of immigrant students is associated with the decline of school resources and quality (empirical regularity 2); the school performance of immigrant children is positively associated with immigration costs (empirical regularity 3); school achievement increases in parental motivation and those immigrant

\footnotetext{
1 To grasp the importance of immigrant children, according to the US Census Bureau, $34 \%$ of all youth aged 15-19 in 2000 were from minority groups and one in five school-age children live in immigrant families (Kao and Thompson 2003). The Innocenti Research Center reports that almost a quarter of children were immigrants in 2009 in the Netherlands, Germany, Sweden and the USA. This proportion is about one-sixth in France and Great Britain (Alba et al. 2011).

2 Studies like those conducted by PISA, and other international organizations (like TIMSS or PIRLS) have allowed for the empirical analysis of immigrant educational success and the externalities imposed on natives. In many countries, a large fraction of immigrant children face substantial disadvantages in reaching educational parity with native children (Heath et al. 2008; Anghel and Cabrales 2014). On the other hand, immigrants often outperform natives students in Australia and Canada (Schnepf 2004). It is also common for some immigrant students to be top of their classes (Card 2005; Dustmann and Theodoropoulos 2010; Dustmann et al. 2010). Immigrant students perform differently by origin group (Levels et al. 2008; Levels and Dronkers 2008) and cross-nationally (Marks 2005).
} 
children with highly motivated parents tend to outperform native children (empirical regularity 4). These (and other) regularities notwithstanding, there is relatively little theoretical work to contextualize the empirical evidence and to inform future empirical investigations. In this paper, we present a tractable model that connects schooling with immigration decisions. Within this framework, we study under which conditions empirical regularities 1, 2, 3 and 4 take place and obtain a number of additional results that highlight that the effect of immigration on native pupils crucially depends on how the school system reacts to immigration-induced changes in classroom composition.

While some of these regularities can be accommodated in other models, ${ }^{3}$ our model can simultaneously produce all of them. Furthermore, the association of school performance with parental immigration cost is unique to our analysis. This regularity must be due to some selection process. ${ }^{4}$ The process we propose is based on selection in terms of (parental) motivation; a term we use to refer to parents' concerns about their children's educational achievement. Parental motivation captures the intrinsic motivation of parents to educate their children and "identified" motivation reflecting parents' perceived value/importance of their involvement for their child's success. ${ }^{5}$ Parental motivation is the most likely driver in the selection process that determines the effect of immigration on the school system; clearly, it is more relevant than child's actual ability, since immigration decisions are made in the absence of a precise signal about the ability of children who might not even be born when the immigration decision is made.

In any theory connecting immigration with schooling, student outcomes must be determined endogenously as a result of the interplay between different families (immigrants and natives) and the school system. In our model, parents (immigrants and native) not only differ in their wages (reflecting different talent or skills), but also in parental motivation. Thus, the schooling effects of immigration depend on parents' characteristics, such as wages and skills, but also on parental motivation. By introducing this dimension into a theory of education and migration choices, we will generate results consistent with the empirical evidence and study what factors induce either positive or negative effects of immigration on the host country's school system.

In our framework, children are short-sighted and need to be motivated to study. Parents divide their time between working and motivating their children, and they decide whether or not to emigrate. Schools provide additional motivational schemes to enhance children's learning effort. The effect of these schemes depends on school resources, which are determined by the education policy. In this framework, learning is a process involving the interaction among children, parents, schools and the decision of school resources. Thus, attainment and school quality are endogenously determined by classroom composition, which is itself affected directly by immigration.

As a necessary result, we show how the educational effect of immigration crucially depends on immigrant parental motivation. We begin by establishing why host countries that are concerned about future human capital would like to attract immigrants

\footnotetext{
3 Regular peer effects for example could explain empirical regularities 1 and 2.

4 We thank an anonymous referee for this observation.

5 Several studies in the psychology literature try to measure this non-observable variable "autonomous motivation" with the help of self determination theory and reveal its importance in terms of parental involvement in their children's learning (Bouchard et al. 2007; Katz et al. 2011; Grolnick 2015).
} 
with high parental motivation. ${ }^{6}$ The reason is that children's learning effort increases in parental motivation; hence, highly motivated immigrant parents are more likely to have skilled children, thereby positively contributing to the future human capital of their host country. This mechanism immediately leads to empirical regularity 4 . The evidence for this observation is vast both in the educational literature and in the economic literature. Parent involvement has been shown to increase children's motivation (e.g., Gonzalez-DeHass et al. 2005; Grolnick and Slowiaczek 1994; Sanders 1998), as well as their grades and achievement, in families of diverse ages and backgrounds (e.g., Fan and Chen 2001; Jeynes 2005, 2007). One important factor is disseminating the importance of education and fostering high expectations about children's school success. By engaging in educational activities with their children, parents communicate their expectations for achievement (Hoover-Dempsey et al. 2001, 2002). The economic literature confirms these findings. The empirical evidence about the effect of exceptionally motivated immigrant parents (as in our empirical regularity 4) is well established in the case of immigration to the USA (see e.g. Glick and White 2004; Hao and Bonstead-Bruns 1998; Keller and Tillman 2008; Goyette and Xie 1999).

By embedding our theory of education into a model of immigration decisions, we identify conditions under which migration is selected by parents with higher parental motivation. These conditions involve a sufficiently high expected absolute skill premium for the immigrant children relative to the parental wage gain from immigration ("Absolute Skill Premium") and sufficiently strong education incentives at the host country ("Education Incentives"); a condition that captures the expected wage of a skilled worker weighed by educational motivation provided by the school. Meeting these conditions implies positive selection in terms of parental motivation within different skill levels. ${ }^{7}$ The empirically observable implication we derive from this result is the above-mentioned empirical regularity 3: the performance at school of immigrant children should be higher when the costs of migrating from the source country are higher, and this stems from their having more highly motivated parents. This result is consistent with Dustmann et al. (2012) and Albornoz et al. (2011). Dustmann et al. (2012) find that Turkish immigrants outperform those of the same cohort who stayed in Turkey, but this empirical observation cannot be explained by the presumably higher quality of the school system at the host countries: Turkish emigrants in Switzerland and Denmark outperform those who migrated to Germany and Austria despite the relatively similar levels of the school quality in these countries. Importantly, this finding is not explained by differences in education levels of parents and socioeconomic

\footnotetext{
6 This is the focus of the present paper. We do not claim that future human capital should be the only concern in immigration policy. Our model is designed to address this issue and is far too simplistic to give a realist picture of other questions.

7 Notice that our notion of positive immigrant selection is very different from the typical notion of positive immigrant selection in terms of skills in the immigration literature as analyzed for example by Borjas (1987, 1999). In this literature, the skill premium is also important: Grogger and Hanson (2011) account for positive selection in terms of skills associated with the absolute difference in earnings of skilled workers at the host and source country. But the only skill premium that matters in this literature would be parental skill premium. In our model, selection crucially depends on parental motivation and the expected skill premium of the children. Notice as well that when these conditions are not satisfied, positive selection requires lowering immigration costs. As we discuss below, this would give support to lenient immigration strategies as those implemented by Argentina.
} 
characteristics. ${ }^{8}$ Our model can explain this finding as migration costs to Switzerland and Denmark are arguably higher than those associated with Germany and Austria; where the Turkish community is large and strong. In Albornoz et al. (2011), we show that immigrant children in the Madrid (Spain) perform better if their parents faced higher immigration costs after controlling for different family and country of origin characteristics such as skills or the education system at the origin country. Our analysis also shows how the exogenous quality of the school system improves immigrant selection in terms of parental motivation.

As documented by many papers Jensen and Rasmussen (2011), Brunello and Rocco (2013), Gould et al. (2009, e.g.), immigration appears to hit native pupils. In our framework, this regularity (empirical regularity 1) is explained by the arrival of immigrants with low motivation. However, we qualify this result. First, a negative selection of immigrant parents reduces the school effort of native students; this hits particularly the native students with relatively low parental motivation. This provides a potential explanation for the negative effect of immigrants on native outcomes being larger for native students from a more disadvantaged socioeconomic background (Gould et al. 2009; Betts 1998; Brunello and Rocco 2011). Second, school quality matters. In our framework, immigrant students, whatever the motivation of their parents, perform better in higher quality schools. Gould et al. (2004) provides empirical support to this feature. Thus, the potential negative effect of immigrant students on their native classmates also depends on the pre-immigration school quality.

We also look at the effect of immigration on school resources in a world where public schools are financed by parents through taxes. We assume that the policy-maker maximizes the utility of the median voter parent, and show that school resources increase in immigrant parental motivation. Hence, a negative selection in parental motivation leads to empirical regularity 2: immigration reduces public resources allocated to education. Evidence of immigration reducing public education expenditures is provided by Dottori et al. (2013), Coen-Pirani (2015) (California), Speciale (2012) (Europe), and Farre et al. (2011) (Spain). Therefore, immigration also affects schooling through the responses of the education policy, not only by the presence of immigrants itself.

In addition to explaining regularities 1,2, 3 and 4, we show that even if a country attracts highly motivated unskilled workers, the responses of native parents to the presence of immigrant pupils matter. Turning to empirical regularity 1 , we show that increasing the share of children of unskilled immigrant parents might create incentives for a flight from some schools into others (private or in other neighborhoods), which would increase segregation. This result connects our paper with an empirical literature analyzing immigration and enrollment in private schools. Betts and Fairlie (2003) find that American-native students fly toward private secondary schools in response to the influx of immigrants into public institutions. Cascio and Lewis (2012) low-skilled immigration reduces native demand for public school in California. Berniell (2010) and Farre et al. (2011) provide similar evidence for the case of Spain in the nineties.

This paper is related to a recent literature that focuses on how the effect of different education policies depends on the behavioral responses of the different actors involved

8 The evidence provided by Dustmann et al. (2012) suggests that there has to be a within skill attribute. 
in the education process. For example, Pop-Eleches and Urquiola (2013) find a positive effect of school quality on student scores for the case of Rumanian high schools. Furthermore, they show as well that parental effort and quality-improving school activities substitute with each other, as in our model. ${ }^{9}$ Stinebrickner and Stinebrickner (2008) and De Fraja et al. (2010) provide empirical evidence on the positive impact of parental and student effort on educational achievement. De Fraja et al. (2010) also find that school motivational activities are positively associated with student scores. ${ }^{10}$ Albornoz et al. (2017) rationalize all these empirical findings in a model that connects the effect of education policy on student outcomes with the behavioral responses of students, teachers, parents and education authorities to policy-driven changes in classroom composition. Our model retains this element but focuses on the endogenous determination of immigration selection and its effects on native students and school quality.

The remainder of the paper is organized as follows. Section 2 introduces the model of parental motivation and the school system. In Sect. 3, we study immigrant selection and discuss under which circumstances higher emigration costs can improve parental selection. Section 4 studies the implications of the model for the school performance of natives and immigrants. Section 5 examines how these implications differ according to the skill composition of immigrant parents. Section 6 looks at the implications of immigration for school resources. Section 7 discusses some immigration policy implications and concludes.

\section{Parental motivation and the school system}

In this section, we develop the basic model of the school system. To fix ideas, we focus on the host country, although our analysis extends straightforwardly to the case of the source country. As in Albornoz et al. (2017), our school system results from the interaction of students (children, who need incentives to put effort on learning), parents (who work and set up costly incentives schemes for students), and teachers/headmasters (who decide on the incentive scheme provided at schools). We also assume that every parent has one child. We now describe our different actors in detail.

\section{The students' utility function:}

The students are children who perceive learning as costly, because they would rather play, and do not internalize the future benefits of studying today. As a consequence, they need to be motivated to exert learning effort. The incentive scheme is put into place by parents and the school. Let $c_{p_{i}}$ be the strength of parental involvement for every unit of child's effort $e_{i}{ }^{11}$ Similarly, $c_{T}$ refers to the strength of the school

\footnotetext{
9 Additional evidence of the substitution between parental effort and school resources is provided by Houtenville and Smith Conway (2008).

10 Sahin (2004) provides another example of how parent and students' responses affect the impact of education policies for the case of higher education tuition subsidies. Evidence of the interaction between parents and the school system mediated by monitoring of schools is offered by Ferreyra and Liang (2012).

11 Parental involvement includes activities at home like supervising children, explicit help with the homework, discussing school issues and providing reward schemes as well as school based activities like volunteering at school, attending school functions. (Hoover-Dempsey and Sandler 1997).
} 
/teacher's involvement. ${ }^{12}$ As suggested by empirical evidence (Houtenville and Smith Conway 2008; Pop-Eleches and Urquiola 2013), we assume that parents and school involvements are substitutes. ${ }^{13}$ We assume that both parental and school involvement enter positively into the children's short-term utility which is given by:

$$
U_{i}^{c}=\left(c_{p_{i}}+c_{T}\right) e_{i}-\frac{1}{2} e_{i}^{2}
$$

where $\frac{1}{2} e_{i}^{2}$ is the cost of learning. ${ }^{14}$

\section{The parents' utility function:}

Unlike children, parents understand the long-term consequences of their children's choices today, namely how the child's learning effort when young influences the child labor market prospects in the future. In particular, the probability that the child will work in a high-skilled job equals the child's learning effort $e_{i}$, while the child will become an unskilled worker with probability $\left(1-e_{i}\right)$. Wages at skilled jobs and unskilled jobs are denoted by $w_{s}$ and $w_{u}$, respectively, and could differ for native and immigrant children (see, e.g., Algan et al. 2010). Hence, a child's future labor market prospect is given by

$$
w_{i}^{c}=w_{s}^{c} e_{i}+\left(1-e_{i}\right) w_{u}^{c} .
$$

Parents differ in their parental motivation ${ }^{15}$ which is modeled as the weight $\theta_{i}$ a parent gives to her child's labor market prospect in her utility function. ${ }^{16}$ Parents also value their own welfare $W_{i}^{P}$. Hence, parental utility is given by

$$
U_{i}^{P}=\theta_{i} w_{i}^{c}+W_{i}^{P}
$$

A parent has to split her total time $T$ between working and setting up and executing an incentive plan for her child. The time to generate the reward is given by $c_{p_{i}} e_{i} / 2$, while the cost of generating incentives for their child is the foregone parental wage $w^{p}$. Our model can be modified to incorporate parental talent ${ }^{17}$ (as Albornoz et al.

12 Schools organize motivational schemes and special outings (e.g., school trips, theater and museum visits) and set learning goals choosing reward schemes.

13 No qualitative change ensues if we assume the incentives to be complementary. This is because the substitutability at the children's utility level is mitigated by complementarities elsewhere. Albornoz et al. (2017) discuss this issue in depth.

14 Instead of using positive reinforcement for learning efforts parents and schools could also work with punishment when children do not study. It is not difficult to see that negative reinforcement induces the same behavior in children than the positive reinforcement we model here.

15 Heterogeneity in parental motivation is one of the major differences of the present model to Albornoz et al. (2017).

16 Empirically, parental motivation is likely to be positively correlated with parental work ethic. Although this link is not captured in the present model, it is easy to extend the model to incorporate work ethic by letting parents allocate their time between leisure, education and work and assuming that the same parameter affects the weight given to education and inversely the enjoyment of leisure. This specification was used in a former version of the model leading to qualitatively similar results.

17 Denote parental talent by $v_{i}^{P}$. On the one hand, parental talent $v_{i}^{P}$ increases wages $w_{i}^{P}=v_{i}^{P} \phi_{i}^{P}$ where $\phi_{i}^{P}$ refers to the parental baseline wage rate. On the other hand, parental talent decreases the time 
2017 do explicitly), and the only major change that arises is that the interpretation of $w^{p}$ would change. Hence, the parental utility function is given by the expression

$$
U_{i}^{P}=\theta_{i}\left(w_{s}^{c} e_{i}+\left(1-e_{i}\right) w_{u}^{c}\right)+\left(T-\frac{1}{2} c_{p_{i}} e_{i}\right) w^{p}
$$

\section{The school's utility function:}

Schools/teachers also fully understand and care about the future job perspectives of their students, assigning weight $\theta^{T}$ to the average student's success. The teachers have to decide how much of the time $T_{T}$ that remains after teaching their compulsory hours they will use to motivate their students (such as training or preparing learning activities), and how much they will use for outside job opportunities (such as private tutoring) which are paid at wage rate $w^{T}$. The teacher's time spent generating the reward $c_{T}$ is equal to $\frac{1}{M} \sum_{i=1}^{M} \frac{1}{2} c_{T} e_{i}$ where $M$ is the total number of children in the classroom. The school/teacher's utility function is therefore

$$
U^{T}=\frac{\theta^{T}}{M} \sum_{i=1}^{M}\left(w_{s}^{c} e_{i}+\left(1-e_{i}\right) w_{u}^{c}\right)+\left(T_{T}-\frac{1}{2 M} \sum_{i=1}^{M} c_{T} e_{i}\right) w^{T}
$$

Let $M=M_{I}+M_{N}$ where $M_{I}$ is the number of immigrant children and $M_{N}$ the number of native children. We can rewrite the school's utility function as ${ }^{18}$

\section{Footnote 17 continued}

parents need to spend for generating their child's incentive reward. This time is now given by $c_{p_{i}} e_{i} / 2 v_{i}^{P}$. Introducing talent into our model would only complicate the exposition but would not affect the main results.

It would, however, help to explain some counterfactual results on topics beyond the scope of the paper. E.g. as it stands, this parental utility function implies that in our model a higher parental wage translates into a lower expected wage of children, and thus lower intergenerational mobility. This would be reverted if parental talent would also help in lowering the cost of motivating children.

18 Here, we assume that wages for immigrant and native children are the same if they have the same job. The model can be easily modified to incorporate different (un)skilled wages for natives and immigrants, respectively. The school's utility function would become

$$
\begin{aligned}
U^{T}= & \frac{\theta^{T}}{M}\left(\left(w_{s}^{c_{N}}-w_{u}^{c_{N}}\right) \sum_{k=1}^{M_{N}} e_{k}+\left(w_{s}^{c_{I}}-w_{u}^{c_{I}}\right) \sum_{i=l}^{M_{I}} e_{l}+w_{u}^{c_{N}} M_{N}+w_{u}^{c_{I}} M_{I}\right) \\
& +\left(T_{T}-\frac{c_{T}}{2 M}\left(\sum_{k=1}^{M_{N}} e_{k}+\sum_{l=1}^{M_{I}} e_{l}\right)\right) w^{T} .
\end{aligned}
$$

where the superscript $c_{N}$ refers to a native child, while the superscript $c_{I}$ to an immigrant child. For simplicity, we stick to the same wage version. This is basically equivalent to having higher wages for natives than immigrants but the same absolute skill premium $w_{s}^{c_{N}}-w_{u}^{c_{N}}=w_{s}^{c_{I}}-w_{u}^{c_{I}}$ since it is the absolute skill premium that provides the incentives for education in the present model. It is not difficult, but notationally cumbersome, to extend the model for different absolute skill premia between immigrants and natives. The qualitative results are basically unchanged. 


$$
\begin{aligned}
U^{T}= & \frac{\theta^{T}}{M}\left(\left(w_{s}^{c}-w_{u}^{c}\right)\left(\sum_{k=1}^{M_{N}} e_{k}+\sum_{i=l}^{M_{I}} e_{l}\right)+w_{u}^{c} M\right) \\
& +\left(T_{T}-\frac{c_{T}}{2 M}\left(\sum_{k=1}^{M_{N}} e_{k}+\sum_{l=1}^{M_{I}} e_{l}\right)\right) w^{T}
\end{aligned}
$$

The structure of the game The school system is modeled as a two-stage game. In the first stage, parents and schools simultaneously decide and announce the optimal strength of their educational involvement in each unit of child's effort: $c_{p_{i}}$ and $c_{T}$, respectively. ${ }^{19}$ After observing these announcements, children decide their optimal effort $e_{i}$.

Equilibrium We solve the game by backward induction.

In the second stage, children choose their optimal effort $e_{i}$ by maximizing their utility function (1) taking parental incentives $c_{p_{i}}$ and school incentives $c_{T}$ as given. This leads to the following optimal effort decision by the children

$$
e_{i}=c_{p_{i}}+c_{T}
$$

In words, children's effort is simply the sum of parental and school educational involvement. We can now turn to the first-stage of the game where we need to substitute this expression (6) into the parent's utility (3) and the school's utility (5). Taking the optimal effort decision of children (6) into account, the teacher's problem is to choose the level of $c_{T}$ that maximizes

$$
\begin{aligned}
U^{T}= & \frac{\theta^{T}}{M}\left(\left(w_{s}^{c}-w_{u}^{c}\right)\left(\sum_{k=1}^{M_{N}}\left(c_{p_{k}}+c_{T}\right)+\sum_{l=1}^{M_{I}}\left(c_{p_{l}}+c_{T}\right)\right)+w_{u}^{c} M\right) \\
& +\left(T_{T}-\frac{c_{T}}{2 M}\left(\sum_{k=1}^{M_{N}}\left(c_{p_{k}}+c_{T}\right)+\sum_{l=1}^{M_{I}}\left(c_{p_{l}}+c_{T}\right)\right)\right) w^{T} .
\end{aligned}
$$

leading to the optimal school involvement/incentives

$$
c_{T}=\frac{\theta^{T}}{w^{T}}\left(w_{s}^{c}-w_{u}^{c}\right)-\frac{M_{N} \overline{c_{p}^{N}}+M_{I} \overline{c_{p}^{I}}}{2 M},
$$

where

$$
\overline{c_{p}^{N}}=\frac{1}{M_{N}} \sum_{k=1}^{M_{N}} c_{p_{k}}^{N}, \overline{c_{p}^{I}}=\frac{1}{M_{I}} \sum_{l=1}^{M_{I}} c_{p_{l}}^{I} .
$$

19 In order to ensure a interior solution, we impose motivation rewards to be positive as to avoid corner solutions where $c_{p_{i}}$ and $c_{T}$ may be zero. 
The strength of the school involvement depends on the average parental involvement of both natives and immigrants, to which we turn now. Parents choose their incentive scheme $c_{p_{i}}$ to maximize

$$
U_{i}^{P}=\theta_{i}\left(w_{s}^{c}\left(c_{p_{i}}+c_{T}\right)+\left(1-\left(c_{p_{i}}+c_{T}\right)\right) w_{u}^{c}\right)+\left(T-\frac{1}{2}\left(c_{p_{i}}+c_{T}\right) c_{p_{i}}\right) w^{p} .
$$

leading to the optimal parental choice

$$
c_{p_{i}}=\left(w_{s}^{c}-w_{u}^{c}\right) \frac{\theta_{i}}{w^{p}}-\frac{1}{2} c_{T}
$$

We define relative parental concern $\psi_{i}$ as the ratio of parental motivation to their wage

$$
\psi_{i}=\frac{\theta_{i}}{w^{p}}
$$

Also, we define the average relative parental concern among the native and foreign population as

$$
\overline{\Omega_{k}}=\frac{1}{M_{k}} \sum_{i=1}^{M_{k}} \frac{\theta_{i}}{w_{i}^{p}}=\frac{1}{M_{k}} \sum_{i=1}^{M_{k}} \psi_{i} \text { for } k=N, I
$$

Using this notation, we can now derive the interior solution of the game.

Lemma 1 For a given school, the optimal strength of parental and school involvement are

$$
\begin{aligned}
& c_{p_{l}}^{j}=\max \left[0,\left(w_{s}^{c}-w_{u}^{c}\right)\left(\psi_{l}^{j}-\frac{2}{3} \frac{\theta^{T}}{w^{T}}+\frac{M_{I} \overline{\Omega_{I}}+M_{N} \overline{\Omega_{N}}}{3\left(M_{N}+M_{I}\right)}\right)\right] \\
& c_{T}=\max \left[0, \frac{2}{3}\left(w_{s}^{c}-w_{u}^{c}\right)\left(\frac{2 \theta^{T}}{w^{T}}-\frac{M_{I} \overline{\Omega_{I}}+M_{N} \overline{\Omega_{N}}}{\left(M_{N}+M_{I}\right)}\right)\right] .
\end{aligned}
$$

where $j=N$ refers to natives and $j=I$ to immigrants.

If both the schools and the child's parent l choose a positive strength of involvement the corresponding child i's effort is

$$
e_{i}^{j}=\left(w_{s}^{c}-w_{u}^{c}\right)\left(\psi_{l}^{j}+\frac{2}{3} \frac{\theta^{T}}{w^{T}}-\frac{M_{I} \overline{\Omega_{I}}+M_{N} \overline{\Omega_{N}}}{3\left(M_{N}+M_{I}\right)}\right) \text { for } j=N, I
$$

\section{Proof See "Appendix 1."}

The above expressions indicate that school and parental involvement are substitutes. Both involvements are driven by the potential gains from education captured 
by $\left(w_{s}^{c}-w_{u}^{c}\right)$. School involvement increase in school motivation $\theta^{T}$ and decrease in teacher's outside job opportunities $w^{T}$ and in average relative parental concern since $\frac{M_{I} \overline{\Omega_{I}}+M_{N} \overline{\Omega_{N}}}{\left(M_{N}+M_{I}\right)}=\frac{1}{M} \sum_{i=1}^{M} \psi_{i}$. The higher this average, which implies the more parents care on average for education, the higher parental involvement in their child's education.

An interior solution (i.e., a solution with $0<e_{i}^{j}<1$ ) exists where both the parents and the school choose positive strengths of learning involvement for some conditions on the distribution of $\psi_{l}^{j}$. Specifically, positive strengths require $\psi_{l}^{j}+\frac{M_{I} \overline{\Omega_{I}}+M_{N} \overline{\Omega_{N}}}{3\left(M_{N}+M_{I}\right)}>$ $\frac{2}{3} \frac{\theta^{T}}{w^{T}}>\frac{M_{I} \overline{\Omega_{I}}+M_{N} \overline{\Omega_{N}}}{3\left(M_{N}+M_{I}\right)}$ which is a relationship comparing parental motivation and their wages with school motivation and wages for outside job opportunities for teachers. Observe that $\frac{\theta^{T}}{w^{T}}$ can be interpreted as a measure of school quality and we will refer to it as net/relative school concern. Hence, the condition for positive incentives can be interpreted as a relationship between school quality measured by the relative school concern and individual and average parental quality measured by the relative individual parental concern and relative average parental concern, respectively.

Until now, we have allowed parental concerns to be unrelated to teachers' concerns. In the real world, there is likely to be a connection. Research in the educational literature suggests that parental motivation positively reinforces the motivation of educators. Bivona (2002) provides evidence showing that the lack of parental involvement is a factor that lowers teacher morale. It is demoralizing for teachers to deal with disinterested parents or, more generally, with student apathy. The positive effect of parental support on teacher job satisfaction has been confirmed in several studies (see Lumsden 1998; Thornton 2004; Perie and Baker 1997 among others). Studies of teacher opinions consistently reflected positive views of active parental involvement in children's education (Cutright 1984; Moles 1982) because a positive teacher experience empowers them to teach more effectively (Lazar and Slostad 1999). A crucial relationship between teachers' sense of efficiency and parental involvement has also been found by Ashton and Webb (1986) and Hoover-Dempsey et al. (1987). This perceived selfefficacy is defined as "people's judgments of their capabilities to organize and execute courses of action required to attain designated types of performances. It is concerned not with skills one has but with the judgments of what one can do with whatever skills one possesses" (Bandura 1986, p. 391). It follows from Bandura (1997)'s work that efficacy is a situation-specific attitude changing with circumstances and events (Grolnick and Slowiaczek 1994) A higher perceived self-efficacy is equivalent to higher motivation: a higher perceived self-efficacy influences the amount of effort a person devotes to the accomplishment of a specific outcome because it is related to a person's inherent beliefs of his or her capabilities to accomplish something, regardless of the person's actual competencies. Ashton and Webb (1986) and Gibson and Dembo (1984) developed empirical constructs of teacher efficacy. Ross (1994) shows that teachers with a higher perceived efficiency level exhibit enhanced student mastery of cognitive and affective goals. The wide-spread research and government programs on how to enhance family-school partnerships are entirely based on this positive link between parental and school motivation (Garcia 2004; Flynn 2011; Sanders 1996; Hoover- 
Dempsey et al. 2002; Oostdam and Hooge 2013 among many others). To capture this positive link formally, we postulate:

Assumption $1 \theta^{T}$ depends on the average parental motivation. That is,

$$
\theta^{T}=k \bar{\theta}=\frac{k}{M} \sum_{i=1}^{M} \theta_{i}
$$

where $M$ is the number of parents affecting the education of a particular school class of children and $k$ indicates the exogenous weight that the school assigns to the future wages of their students.

We are now in a position to analyze how parental motivation in general and immigrants' parental motivation in particular affect the quality of the school system. In all our further analyses, Assumption 1 is crucial whenever the result is qualitatively valid only if school motivation increases in parental motivation (as in Propositions 1 and 8, as well as as Lemma 3 and the discussion after Lemma 4 below). But as we just argued extensively, the assumption is well founded empirically.

Using Assumption 1 in Eq. (12), we can express the optimal strength of school involvement as:

$$
c_{T}=\max \left[0, \frac{2\left(w_{s}^{c}-w_{u}^{c}\right)}{3 M} \sum_{i=1}^{M}\left(\left(\frac{2 k}{w^{T}}-\frac{1}{w^{p_{i}}}\right) \theta_{i}\right)\right]
$$

Hence, schools will only choose a positive strength of involvement if

$$
\sum_{i=1}^{M}\left(\frac{2 k}{w^{T}}-\frac{1}{w^{p_{i}}}\right) \theta_{i}>0
$$

In words, parental involvement will not crowd out school involvement if the relative school concern is at least half the size of the average relative parental concern. Schools must care sufficiently about their students' performance. Moreover,

Proposition 1 School involvement $c_{T}$ increases in parental concern $\theta_{i}$ if and only if $w^{p}>\frac{w^{T}}{2 k}$.

Proof To see how positive school involvement changes with parental motivation, we need to look at

$$
\operatorname{sign} \frac{\partial c_{T}}{\partial \theta_{i}}=\operatorname{sign}\left(\frac{2 k}{w^{T}}-\frac{1}{w_{i}^{p}}\right)
$$

which tells us that school involvement (15) increases in parental motivation for parents whose wages are such that $2 k / w^{T}>1 / w_{i}^{p}$

The ratio $\frac{k}{w^{T}}$ is the exogenous term determining the net school concern $\frac{\theta^{T}}{w^{T}}=\frac{k}{w^{T}} \bar{\theta}$ and can therefore be interpreted as the exogenously given school quality. It is also 
(proportional to) the marginal effect of parental motivation of parent $i$ on the net school concern, while the marginal effect on average relative parent concern is (proportional to) $\frac{1}{w^{p_{i}}}$. The condition of Proposition 1 relates parental wage, namely the opportunity cost of parental involvement, to the inverse of exogenous school quality which is the ratio of the school's opportunity cost of teacher's involvement to the weight schools give to the future performance of their students. A higher parental concern will increase parental involvement, but this increase might affect school involvement negatively since parental and school involvement are substitutes. A sufficiently high exogenous school quality makes school involvement more valuable and allows for both parental and school involvement to increase in parental concern. Therefore, the lower bound on parental wage for school involvement to increase in parental concern is proportional to the inverse of exogenous school quality.

Assumption 1 allows us to characterize how a child's learning effort depends on parental motivation, namely

$$
e_{i}=\left(w_{s}^{c}-w_{u}^{c}\right)\left(\frac{\theta_{i}}{w_{i}^{p}}+\frac{1}{3 M} \sum_{j=1}^{M}\left(\frac{2 k}{w^{T}}-\frac{1}{w_{j}^{p}}\right) \theta_{j}\right),
$$

From this equation, it is straightforward to establish:

Proposition 2 Children's learning effort is always increasing in parental motivation $\theta_{i}$.

Proof This follows from $\frac{\partial e_{i}}{\partial \theta_{i}}>0$

Propositions 1 and 2 reveal the crucial role of parental concern/motivation. On the one hand, more motivated parents produce children with higher learning efforts, which is clearly related to our empirical regularity 4 (parental motivation is also emphasized by, for example, Doepke and Zilibotti 2014). On the other hand, if schools have a sufficiently high exogenous quality, more motivated parents have a positive spillover on the entire system by leading to a higher school involvement $c_{T}$. Therefore, immigrationreceiving countries would like to attract immigrants with a high parental concern.

\section{Immigrant self-selection}

In this section, we study the immigration decision. There are two countries: Home $(H)$, the source or origin country, and Abroad $(A)$, the destination or host country. Each parent $i$ in country $H$ faces a fixed cost of immigration $F_{i}$. The variable $F_{i}$ follows the distribution $F($.$) in a large compact interval. Immigration policies may$ affect this distribution in various ways, and we clarify their impact in terms of whether they induce immigration to have a positive impact on the school system.

Both countries have a skilled and unskilled labor market, and their schools system can be described by the model of the previous section. ${ }^{20}$ However, they may differ

20 We are implicitly assuming that how learning incentives translate into the probability of getting a skilled job in the country in which education was received is the same across countries. The crucial element in our analysis is that learning effort is endogenously determined according to different country characteristics. 
in the economic opportunities and the quality of the school system. Based on these parameters, parents estimate the expected utilities of both staying and leaving their country of origin. Immigration requires the utility difference to be higher than the immigration cost.

Let $U_{P_{i}}^{j}$ denote parental utility when living within country $j$, namely

$$
U_{P_{i}}^{j}=\theta_{i}\left(e_{i}^{j}\left(w_{s_{j}}^{c}-w_{u_{j}}^{c}\right)+w_{u_{j}}^{c}\right)-\frac{1}{2} c_{p_{i}}^{j} e_{i}^{j} w_{j}^{p_{i}}+T w_{j}^{p_{i}} \quad \text { for } j=H, A
$$

Using the optimal involvement and effort decisions derived in Lemma 1, the parental utility after some simplification becomes

$$
U_{P_{i}}^{j}=T w_{j}^{p_{i}}+\theta_{i} w_{u_{j}}^{c}+\frac{w_{j}^{p_{i}}}{2}\left(e_{i}^{j^{*}}\right)^{2} \text { for } j=H, A
$$

where $e_{i}^{j^{*}}$ is the optimal learning effort of $i^{\prime} s$ child when schooled in country $j$ which by (13) is

$$
e_{i}^{j^{*}}=\left(w_{s_{j}}^{c}-w_{u_{j}}^{c}\right)\left(\psi_{l}^{j}+\frac{2}{3} \frac{\theta_{j}^{T}}{w_{j}^{T}}-\frac{\overline{\Omega_{j}}}{3}\right) \text { for } j=H, A
$$

where $\overline{\Omega_{j}}=\frac{1}{M_{j}} \sum_{k=1}^{M_{j}} \psi_{k}^{j}$ is the average relative parental concern in a school in country $j$. We can therefore write parental utility as

$$
\begin{aligned}
U_{P_{i}}^{j}= & T w_{j}^{p_{i}}+\theta_{i} w_{u_{j}}^{c} \\
& +\frac{\left(w_{s_{j}}^{c}-w_{u_{j}}^{c}\right)^{2}}{2}\left(\frac{\theta_{i}^{2}}{w_{j}^{p_{i}}}+2 \theta_{i}\left(\frac{2}{3} \frac{\theta_{j}^{T}}{w_{j}^{T}}-\frac{\overline{\Omega_{j}}}{3}\right)+w_{j}^{p_{i}}\left(\frac{2}{3} \frac{\theta_{j}^{T}}{w_{j}^{T}}-\frac{\overline{\Omega_{j}}}{3}\right)^{2}\right)
\end{aligned}
$$

Observe that the first term of parental utility $T w_{j}^{p_{i}}$ corresponds to the maximum earnings from working (what a parent can get by working all the time), while the second term $\theta_{i} w_{u_{j}}^{c}$ reflects the parental utility if the child does not make any educational effort. Parental involvement in the child's education increases the parental utility whenever future skilled jobs are better paid than future unskilled jobs; that is if $w_{s_{j}}^{c}>w_{u_{j}}^{c}$ as is reflected in the third term of (20).

A parent $i$ will emigrate from country $H$ to country $A$ if $U_{P_{i}}^{A}-F_{i}>U_{P_{i}}^{H}$. From (20), it follows that

Lemma $2 U_{P_{i}}^{A}-F_{i}>U_{P_{i}}^{H}$ if and only if

$$
\begin{aligned}
T & \left(w_{A}^{p_{i}}-w_{H}^{p_{i}}\right)+\theta_{i}\left(w_{u_{A}}^{c}-w_{u_{H}}^{c}\right) \\
+ & \frac{\theta_{i}^{2}}{2}\left(\frac{\left(w_{s_{A}}^{c}-w_{u_{A}}^{c}\right)^{2}}{w_{A}^{p_{i}}}-\frac{\left(w_{s_{H}}^{c}-w_{u_{H}}^{c}\right)^{2}}{w_{H}^{p_{i}}}\right)
\end{aligned}
$$




$$
\begin{aligned}
& +\theta_{i}\left(\left(w_{s_{A}}^{c}-w_{u_{A}}^{c}\right)^{2}\left(\frac{2}{3} \frac{\theta_{A}^{T}}{w_{A}^{T}}-\overline{\Omega_{A}}\right)-\left(w_{s_{H}}^{c}-w_{u_{H}}^{c}\right)^{2}\left(\frac{2}{3} \frac{\theta_{H}^{T}}{w_{H}^{T}}-\frac{\overline{\Omega_{H}}}{3}\right)\right) \\
& +\frac{1}{2}\left(w_{A}^{p_{i}}\left(\frac{2}{3} \frac{\theta_{A}^{T}}{w_{A}^{T}}-\frac{\overline{\Omega_{A}}}{3}\right)^{2}\left(w_{s_{A}}^{c}-w_{u_{A}}^{c}\right)^{2}\right. \\
& \left.-w_{H}^{p_{i}}\left(\frac{2}{3} \frac{\theta_{H}^{T}}{w_{H}^{T}}-\frac{\overline{\Omega_{H}}}{3}\right)^{2}\left(w_{s_{H}}^{c}-w_{u_{H}}^{c}\right)^{2}\right) \\
& >F_{i} .
\end{aligned}
$$

Since the primary motive for emigration is the possibility of better economic opportunities, we assume that wages abroad are at least as high as wages at home and one of the three wage parameters (expected parental wage $w^{P_{i}}$, expected child's wage if skilled $w_{s}^{c}$ and if unskilled $w_{u}^{c}$ ) must be strictly higher. Then, we can interpret the condition for immigration in Lemma 2 as follows: $T\left(w_{A}^{p_{i}}-w_{H}^{p_{i}}\right)+\theta_{i}\left(w_{u_{A}}^{c}-w_{u_{H}}^{c}\right)$ describes the wage gain due to immigration if the immigrant parent dedicates all the time to work. The parent might get a higher expected pay $w_{A}^{P_{i}} \geq w_{H}^{P_{i}}$, and the unskilled child might also earn more money $w_{u_{A}}^{c} \geq w_{u_{H}}^{c}$ which is weighted by the parental concern parameter $\theta_{i}$. The remaining 3 lines of the sum describe the change in parental utility from emigrating that is achieved by incentivizing the child at school and can be rewritten as $\frac{w_{A}^{p_{i}}}{2} e_{A}^{2}-\frac{w_{H}^{p_{i}}}{2} e_{H}^{2}$ (see Eq. 19). Parents and schools want to incentivize children to increase their chance to get a high-skilled job, which is why the absolute difference between skilled and unskilled wages enters in the three parts of the sum that corresponds to the parental utility derived from the child's effort. Since the parental wage is the opportunity cost of parental involvement in incentivizing the child, a higher wage has a negative effect on effort as captured by $w^{p_{i}}$ dividing in the second line of the sum. However, since school involvement and parental involvement are substitutes, a higher $w^{p_{i}}$ has an indirect effect by increasing effort that is captured by the final line of the sum. The third term of the sum captures the change in parental utility due to a change in school quality combined with the incentives for education.

Suppose the heterogeneity is such that the vector of variables

$$
\xi_{i} \equiv\left(\theta_{i}, w_{A}^{p_{i}}, w_{H}^{p_{i}}\right) \in \Xi
$$

characterizes each individual belongs to a finite set of types $\Xi$. At the same time, the variable $F_{i}$ follows the distribution $\mathcal{F}($.) in the compact interval $[0, \mathcal{A}]$, where we assume $\mathcal{A}>\max _{\xi_{i} \in \Xi} U_{P_{i}}$. Note that according to Eq. (21) if an individual with type $\xi_{i}$ and value for the cost of moving $F_{i}$ wants to move, another individual with type $\xi_{j}=\xi_{i}$ and $F_{j}<F_{i}$ also wants to move. Hence, the equilibrium can be characterized by a set of thresholds. For each type $\xi \in \Xi$, there is some $F_{\xi}$ such that for all $i$ with $\xi_{i}=\xi \in \Xi$ the individual moves to $A$ if and only if $F_{i}<F_{\xi}$. Thus,

Proposition 3 An equilibrium in immigration decisions always exists.

Proof See "Appendix 2." 
Understanding the effects of differences in parental motivation on the host and source countries requires further clarification about how individuals from $\mathrm{H}$ self-select into the migrant population. We turn to this question in the following subsections.

\subsection{When immigration does select the most motivated parents}

We aim at identifying the conditions under which the most motivated parents from a source country are those who self-select into immigration. As migrating is an individual decision, potential immigrants take $\Omega_{A}$ and $\Omega_{H}$ as given. This is the same as assuming:

$$
\frac{\partial \overline{\Omega_{A}}}{\partial \theta_{\xi}}=\frac{\partial \overline{\Omega_{H}}}{\partial \theta_{\xi}}=0
$$

Using the link of school motivation to parental motivation stipulated in Assumption 1 and the condition for immigration stated in Lemma 2, we obtain the following crucial result:

Proposition 4 Assume that wages in the host country are at least as high as wages in the source country. Then, for any skill level, immigrant selection is positive in parental motivation if the following conditions are satisfied:

1. Absolute Skill Premium:

$$
\frac{\left(w_{s_{A}}^{c}-w_{u_{A}}^{c}\right)}{\left(w_{s_{H}}^{c}-w_{u_{H}}^{c}\right)}>\sqrt{\frac{w_{A}^{p_{i}}}{w_{H}^{p_{i}}}}
$$

2. Education Incentives:

$$
\begin{aligned}
& w_{u_{A}}^{c}+\frac{1}{3}\left(w_{s_{A}}^{c}-w_{u_{A}}^{c}\right)^{2}\left(\frac{2 k_{A}}{w_{A}^{T}} \overline{\theta_{A}}-\overline{\Omega_{A}}\right) \\
& \geq w_{u_{H}}^{c}+\frac{1}{3}\left(w_{s_{H}}^{c}-w_{u_{H}}^{c}\right)^{2}\left(\frac{2 k_{H}}{w_{H}^{T}} \overline{\theta_{H}}-\overline{\Omega_{H}}\right)
\end{aligned}
$$

Proof It follows from inspection of Eq. (21). See "Appendix 3" for the details.

The ratio of absolute skill premium for children between the receiving and sending countries has to be higher than the (square root of) ratio of parental wages in sending and receiving countries (the gain from immigration). ${ }^{21}$ This condition places an upper bound on parental wages abroad, which nicely captures the trade-off parents face when incentivizing their children: forgo parental wage versus higher expected wages for their children. A sufficiently high absolute skill premium for children guarantees that parents incentivize their children more abroad than at home. But this is not sufficient

21 Notice that this condition can be satisfied even if the relative skill premium is lower in the host country. We are interested in the future human capital of children and therefore in parental selection, for which the absolute skill premium for children matters more. Grogger and Hanson (2011) document the importance of the absolute skill premium for parents to explain immigrant selection in parental education. 
for positive parental selection. The external environment at the host country has to be sufficiently favorable. To see this, notice that condition (23) can be reformulated as:

$$
w_{u_{A}}^{c}+\frac{1}{2}\left(w_{s_{A}}^{c}-w_{u_{A}}^{c}\right) c_{T}^{A^{*}} \geq w_{u_{H}}^{c}+\frac{1}{2}\left(w_{s_{H}}^{c}-w_{u_{H}}^{c}\right) c_{T}^{H^{*}}
$$

Thus, we can interpret education incentives as a measure of the expected wage increase for a skilled child weighted by the education incentives provided by the school. This measure has to be higher at the host country. It is instructive to consider a situation in which both countries are identical except for their wage structure. More technically,

Corollary 1 If the host and the source countries have the same exogenous quality of the school system $\left(2 k_{A} / w_{A}^{T}=2 k_{H} / w_{H}^{T}\right)$; the same initial distribution of parental motivation; the same distribution of parental motivation among skill groups; and the same proportion of people in skilled employment, then a higher absolute skill premium at the host country is sufficient for inequality (23) to hold.

Proof Notice that due to the equality in exogenous school quality

$$
\left(\frac{2 k_{A}}{w_{A}^{T}} \overline{\theta_{A}}-\overline{\Omega_{A}}\right)>\left(\frac{2 k_{H}}{w_{H}^{T}} \overline{\theta_{H}}-\overline{\Omega_{H}}\right) \Leftrightarrow \overline{\Omega_{A}} \leq \overline{\Omega_{H}},
$$

or equivalently

$$
\frac{1}{M_{H}} \sum \theta_{i} / w_{H}^{p_{i}} \geq \frac{1}{M_{A}} \sum \theta_{j} / w_{A}^{p_{i}} .
$$

This is true since wages in country $A$ are at least as high as wages in country $H$, and the distribution of parental motivation among skill groups is identical.

Obviously, if the exogenous school quality is better abroad than at home so that $2 k_{A} / w_{A}^{T}>2 k_{H} / w_{H}^{T}$, condition (23) is relaxed. This result suggests that immigration is more likely to positively select motivated parents when the host country pays a higher future absolute skill premium and school quality is better, provided that intrinsic parental motivation is not much higher in the source country. Arguably, this describes a situation where immigrants arrive to highly developed countries from developing countries.

Proposition 4 sheds light on how immigration policies that affect immigration costs for all immigrants influence the selection of immigrants and consequently the educational performance of immigrant children, which is increasing in parental motivation. Notice that conditions (22) and (23) being satisfied characterize a situation where highly motivated parents enjoy relatively higher benefits from emigrating. As a consequence, selection improves with higher emigration costs. This implies the following two results that provide a theoretical explanation for the aforementioned empirical regularity 3. The proof of Propositions 5 and 6 follows directly from (21) and Proposition 2.

Proposition 5 For a given host country, immigrant children who perform better are those whose parents faced the higher emigration costs. 
In Albornoz et al. (2011), we provide empirical support to this result. More precisely, we present novel empirical evidence according to which immigrant performance in the standardized exams for all primary schools in the Madrid region do indeed improve with emigration costs. Proposition 4 also implies the flip-side of the argument:

Proposition 6 For a given origin country, immigrant children perform better in host countries for which the emigration costs are higher.

An interesting case consistent with this result is provided by Dustmann et al. (2012), who show that Turkish immigrant children not only outperform kids staying in Turkey but also their student achievement varies across four countries with relatively similar education quality: Germany, Austria, Switzerland and Denmark. According to Dustmann et al. (2012), Turkish immigrant children do considerably better in Switzerland and Denmark compared to similar Turkish immigrant children in Germany and Austria - conditional and unconditional on parental background characteristics and the quality of schools they attend. Given that migration costs from Turkey are arguably higher for Switzerland and Denmark than for Germany and Austria, this corollary provides an explanation to this fact. ${ }^{22}$

Hence, our model generates empirical regularity 3, but also contextualizes under which conditions the observable evidence is consistent in equilibrium. Moreover, in situations where conditions of Proposition 4 fail, immigration no longer selects the most motivated parents. To this we turn now.

\subsection{When immigration does not select the most motivated parents}

In this section, we briefly discuss the cases where the conditions for a positive selection of immigration in terms of parental motivation no longer hold. In these cases, migrants are not among those who are more motivated and thus the effect of immigration on the school system will be negative.

When both condition (22) and condition (23) are violated, both the parental tradeoff, and the external education incentives are worse abroad than at home. This typically happens because the benefits from education abroad (the absolute skill premium) are lower than at home. Hence, the incentives to educate children are weaker. Moreover, unskilled wages abroad cannot be much higher than at home. For this reason, parents with higher parental concerns would not migrate and immigrant selection would likely fall on the least motivated parents.

When condition (22) is violated but (23) is satisfied, parental selection is likely to fall on intermediate levels of parental motivation. On the one hand, the tension between parental wages abroad and the child's future wages is resolved in such a way that parents work more hours and incentivize their children less, which is a loss for motivated parents. On the other hand, the external environment children face abroad is more favorable, which is a gain for motivated parents. These two countervailing

\footnotetext{
22 The size of the Turkish community in Germany and Austria provides a reason why the migration costs from Turkey might be lower in these countries. Language distance between Danish and Turkish and relatively more strict immigration laws in Switzerland provide additional reasons.
} 
forces are likely to prevent the most motivated and the least motivated parents from emigrating.

When condition (22) is satisfied but (23) is violated, parents set higher education incentives abroad than at home, but the external environment for children is worse abroad. The benefits of immigration (which are a quadratic function of $\theta$ ) first fall in parental motivation till they reach a minimum and then rise again. Hence, parents willing to emigrate are likely to fall into the extreme ends of the distribution of parental motivation. Observe that this case only happens rarely. To see this, recall that $w_{u_{A}}^{c}>w_{u_{H}}^{c}$ by assumption, hence $\left(w_{s_{A}}^{c}-w_{u_{A}}^{c}\right)>\left(w_{s_{H}}^{c}-w_{u_{H}}^{c}\right)$ is a necessary (but not sufficient) condition for condition (22) to hold. This implies that the returns to education are higher abroad, which positively affect both parental incentives and school incentives. Therefore, condition (23) can only be violated if external school quality and average parental motivation at home is much higher than abroad, and unskilled wages are very similar. But in this case also the last line of the condition to emigrate given by (21) will become negative and even very low $F_{i}$ might not be sufficient to induce emigration. ${ }^{23}$

The empirical implications of the model can change considerably if we look at host and origin countries where condition (22) is violated. This happens for example if it is mainly the unskilled jobs that are better paid in the destination country than in the origin country. If condition (23) is also violated, it makes sense for the destination country to adopt policies that reduce immigration costs in order to be able to attract also immigrants with a high parental motivation, irrespectively of their level of skills. An example of this situation is given by the immigrants hosted in Argentina from countries like Bolivia, Peru or Paraguay Gasparini et al. (2009). These origin countries are characterized by a very high differences between skilled and unskilled wages, certainly as high as in Argentina. Also, the wages in Argentina are not that much higher. This gives some theoretical support to the immigration strategy of Argentina, which has one of the most lenient immigration regulations in the world (Albarracín 2004).

If (23) holds, selection falls on the intermediate range of parental motivation. In this case, whether it is good for a country to adopt policies that reduce or increase immigration costs depends on the exact distribution of $\theta$. Under intermediate selection, a decline in immigration costs will expand the interval of values of $\theta$ for which emigration occurs at both extremes which can influence in either direction the immigrants' average level of $\theta$. More specifically, if $\theta$ follows a non-increasing density function, then a reduction in immigration costs induces a decline in the average level of $\theta$ (McKenzie and Rapoport 2010).

The above results indicate that immigration policies should be specific to the country of origin. For origin countries where both the condition on the absolute skill premium (22) and the condition on the external education incentives (23) are satisfied, imposing additional costs will improve immigrant selection in parental motivation. Otherwise, lowering immigration costs but setting strict and low quotas might be the better policy.

23 Observe that at least for low-skill immigrants, the main economic motive for immigration reflected by the value of $T\left(w_{A}^{p_{i}}-w_{H}^{p_{i}}\right)$ will also be very low. 


\subsection{School quality}

In the previous section, incentives to immigrate were both shaped by the economic incentives and possibly the difference in school systems. It will be useful to understand the effect of differences in school quality in isolation. In order to do so, we assume that school quality is the only difference between $H$ (Home) and $A$ (Abroad) and that school quality is better abroad, i.e., $\left(\frac{2}{3} \frac{\theta_{A}^{T}}{w_{A}^{T}}-\frac{\overline{\Omega_{A}}}{3}\right)>\left(\frac{2}{3} \frac{\theta_{H}^{T}}{w_{H}^{T}}-\frac{\overline{\Omega_{H}}}{3}\right)$. Under these assumptions, immigration occurs if (21) holds which reduces to

$$
\begin{aligned}
& \theta_{i}\left(w_{s}^{c}-w_{u}^{c}\right)^{2}\left(\left(\frac{2}{3} \frac{\theta_{A}^{T}}{w_{A}^{T}}-\frac{\overline{\Omega_{A}}}{3}\right)-\left(\frac{2}{3} \frac{\theta_{H}^{T}}{w_{H}^{T}}-\frac{\overline{\Omega_{H}}}{3}\right)\right) \\
& \quad+\frac{1}{2}\left(w_{s}^{c}-w_{u}^{c}\right)^{2} w^{p_{i}}\left(\left(\frac{2}{3} \frac{\theta_{A}^{T}}{w_{A}^{T}}-\frac{\overline{\Omega_{A}}}{3}\right)^{2}-\left(\frac{2}{3} \frac{\theta_{H}^{T}}{w_{H}^{T}}-\frac{\overline{\Omega_{H}}}{3}\right)^{2}\right) \\
& >F_{i} .
\end{aligned}
$$

which after some examination implies:

Proposition 7 The cost that a parent is willing to pay to immigrate increases in school quality, but it increases proportionally more for parents with higher motivation.

Proof It is easy to see that the cross derivative of left-hand side of (25) with respect to $\theta$ and $\frac{2}{3} \frac{\theta_{A}^{T}}{w_{A}^{T}}-\frac{\overline{\Omega_{A}}}{3}>\frac{2}{3} \frac{\theta_{H}^{T}}{w_{H}^{T}}-\frac{\overline{\Omega_{H}}}{3}$ is positive.

In other words, if immigration costs increase, but at the same time school quality increases, the selection of immigrants should improve since those that get discouraged with the higher costs are more likely to be those for whom the increase in school quality matters less. Although we do not believe that school quality per se is the main reason of emigration for the majority of people who leave their country, the result nevertheless has an interesting testable implication: the school performance of immigrant children should be better in countries with higher immigrations costs and high quality (public) schools. Gibson and McKenzie (2011) provide some evidence for this prediction: they show that the quality of Australian schools is a key pull factor for the most qualified immigrants arriving from New Zealand, Tonga and New Guinea Papua.

\section{The school performance of immigrant and native children}

Our model reveals that the effect of the immigration on the school system depends on the type of parents that immigrate. It can therefore guide us to understand empirical observations on immigrant school performance and their effects on native performance.

In empirical studies, student outcomes constitute a typical empirical measure of school quality. Since these outcomes depend on children's learning effort, we now examine this effort in more detail. It is clear from Eq. (13) that among children in 
the same school it is their parents' characteristics $\psi_{i}$, namely the relative parental concern - the net pay-off from parental investment, that determines who has the higher learning effort. If we apply this to the difference in learning effort between an immigrant child and a native child, then

$$
e_{i}^{I}-e_{j}^{N}=\left(\psi_{i}^{I}-\psi_{j}^{N}\right)\left(w_{s}^{c}-w_{u}^{c}\right)
$$

which implies that the effort of immigrant children is greater than of natives on average if and only if $\overline{\Omega_{I}}>\overline{\Omega_{K}}$. Having established this, the next proposition follows immediately:

Proposition 8 The children of immigrants exert more effort at a given school than natives if and only if the average relative parental concern is higher among immigrant parents than natives. ${ }^{24}$

Therefore, immigrant children performing below average is a sign that immigration policies do not select on average the most motivated parents. Similarly, we can conclude that a highly performing immigrant child will have highly motivated parents. Indeed, Proposition 2 reveals that a higher parental motivation always translates into a better performing child via a higher education effort. From Proposition 1, we know that school involvement only increases in parental motivation of parents whose wage is not too low, in particular for parents where $w^{p}>\frac{w^{T}}{2 k}$. Schools will still set incentive schemes for their students when this condition is violated for some parents but is satisfied for a sufficient amount of parents (technically, condition (16) holds). Highly motivated parents with too low wages in these types of schools have a negative effect on school involvement, but the direct effect of rising parental involvement on student effort offsets this negative impact on the school. Hence, the greater learning effort of children from highly motivated parents must come because of the parents' higher demands. The empirical evidence about the effect of exceptionally motivated immigrant parents (as in our empirical regularity 4) is vast in the case of immigration to the US. As shown by Glick and White (2004) and Hao and Bonstead-Bruns (1998), immigrant parents are associated with greater demands on their children in terms of school engagement and academic achievement. Keller and Tillman (2008) find that both parental and self-reported expectations have significant direct effects on college attendance. Goyette and Xie (1999) provide evidence that in the USA the behaviors and expectations of Asian immigrant parents' tend to raise their children's school attendance above the average.

The net parental concern $\psi_{i}=\frac{\theta_{i}}{w^{p_{i}}}$ also plays an important role in explaining the variation in school performance of native children due to immigration. Observe that we can rewrite the child's effort (17) as

$$
e_{i}=\left(w_{s}^{c}-w_{u}^{c}\right) \psi_{i}+\frac{1}{2} c_{T}
$$

\footnotetext{
24 While Proposition 8 is stated for the school level, it generally holds when the environment of immigrants and natives are the same. In a country as a whole, it would hold if all schools are the same and immigrants and natives are equally distributed among schools.
} 
This expression allows us to analyze how immigration affects the performance of native pupils and contextualize the emergence of empirical regularity 1 and clarifies under which conditions this observation is consistent with an equilibrium in our model. For a given school, the relative effect of immigration on native children varies with the net parental concern. A change in $c_{T}$ simply shifts the initial effort up (if immigrant parents are better on average) or down (otherwise), and therefore the relative change in effort is lower the higher the pre-immigration effort level or equivalently, for children associated with a higher $\psi_{i}$. In other words, the performance of disadvantaged children (low $\psi_{i}$ parents) is more affected by immigration than that of their more advantaged classmates (high $\psi_{i}$ parents). The evidence for this effect is considerable. Focusing on the mass migration wave from the former Soviet Union to Israel in the early 1990s, Gould et al. (2009) find a negative effect of immigrants on native outcomes which is larger for natives from a more disadvantaged social background. Similarly, Betts (1998) shows that immigration reduces the probability of completing high schools for American-native minorities (Blacks and Hispanics). No negative effect of immigrants is found for non-minority groups. Finally, Brunello and Rocco (2011) study whether a higher share of immigrant pupils affects the school performance of natives using aggregate multi-country data from PISA. They find evidence of a negative and statistically significant relationship, but the size of the estimated effect is small and it is bigger for natives with a relatively disadvantaged parental background. ${ }^{25}$

Expression (26) also allows us to examine the effect of schools on immigrant performance. A typical measure of school quality is the pre-immigration performance or general performance of its native pupils. As discussed above, overall native performance is partly driven by $c_{T}$. According to (26), a higher level of $c_{T}$ would benefit all children at the school, and hence this would include the immigrant children. This is consistent with the vast evidence suggesting that better schools benefit immigrants (Dronkers and Fleischmann 2010). The "Operation Solomon" provides a natural experiment for this result. This refers to the exodus of 15,000 Ethiopian immigrants, who were airborne to Israel within 36 h in May 1991. Importantly, they were randomly sorted across the country. According to our model, the average performance of those immigrants who were randomly placed into better schools should be higher. As shown by Gould et al. (2004), this was exactly the case: those Ethiopians who were assigned to better elementary schools ${ }^{26}$ had better results in high school. Thus, empirical regularity 1 is an equilibrium outcome, but it depends on pre-immigration school quality.

\section{The effect of immigrant skill composition}

Parental net concern reflects both parental skills which determine parental wages and pure parental motivation. This section disentangles the two parameters and serves to

\footnotetext{
25 Similarly, Ohinata and van Ours (2011) find no evidence of negative spillovers of immigrants on native Dutch children. They do find, however, that the share of immigrants in a classroom is negatively associated with the reading scores of immigrant children.

26 The measure of better elementary schools used by Gould et al. (2004) was the average standardized maths scores before Ethiopian entered or other environmental measures such as welfare rate and average high school matriculation rate.
} 
illustrate how different skill compositions effect the school system of the immigrationreceiving country and why. We first reformulate our results when schools' involvement in providing incentives is positive (Eq. 16) and how it varies with parental motivation (Proposition 1) in a world where parents can have skilled and unskilled jobs.

Lemma 3 In a school with $M^{U}$ unskilled and $M^{S}$ skilled parents with corresponding wages $w_{u}^{p}$ and $w_{s}^{p}=\alpha w_{u}^{p}$, where $\alpha>1$, the school will choose a positive learning involvement if

$$
w_{s}^{p}=\alpha w_{u}^{p}>\frac{w^{T}}{2 k}
$$

and

$$
w_{u}^{p}>\frac{(\beta+\alpha) w^{T}}{2(1+\beta) k \alpha}
$$

where $\beta=\sum_{i=1}^{M^{S}} \theta_{i} / \sum_{i=1}^{M^{U}} \theta_{i}$.

The school's learning involvement always increases in the parental motivation of skilled parents. If

$$
w_{u}^{p}>\frac{w^{T}}{2 k}
$$

school involvement also increases in parental motivation of unskilled parents. However, if (29) fails, then school involvement decreases in the parental motivation of unskilled parents.

Lemma 3 reveals that if unskilled wages are too low relative to the exogenous opportunity cost of schools to incentivize children (Condition (29) fails), then increasing parental motivation among unskilled parents will reduce school quality. In this case, positive school incentives require a sufficiently high-skill premium captured by the parameter $\alpha$. A higher $\alpha$ relaxes both conditions (27) and (28) and hence favors school involvement in incentivizing students. The parameter $\beta$ compares total parental motivation of skilled parents with total parental motivation of unskilled parents and $\beta>1$ if the former is bigger than the latter. A higher $\beta$ relaxes (28). The skilled group is sufficiently motivated so that the resulting positive effect on school incentive outweighs a potential negative effect of the unskilled parental group due to the violation of condition (29).

In the case where highly motivated unskilled parents have a negative effect on the school involvement and therefore impose negative externalities to the remaining parents, it is important to distinguish parental skill from pure parental motivation. The need for this distinction becomes even more crucial when immigration changes classroom composition. To see why assume that (29) holds, which is likely in developed countries which are targeted by immigration since these countries typically have a reasonable exogenous level of school quality $\left(2 k / w^{T}\right)$. In other words, keeping the skill level constant an increase in pure parental concern is always beneficial for school involvement in providing incentives. However, things might look very different if 
immigration changes the skill composition at school. ${ }^{27}$ In a world with skilled and unskilled workers, school incentives can also be rewritten as

$$
c_{T}=\frac{2\left(w_{s}^{c}-w_{u}^{c}\right)}{3\left(M^{U}+M^{S}\right)}\left(\left(\frac{2 k}{w^{T}}-\frac{1}{w_{u}^{p}}\right) M^{U} \overline{\theta^{U}}+\left(\frac{2 k}{w^{T}}-\frac{1}{\alpha w_{u}^{p}}\right) M^{S} \overline{\theta^{S}}\right) .
$$

This expression allows us to disentangle the effect of only high skill and only lowskill immigrations assuming a constant classroom size. If immigrants are positively selected according to parental motivation and are only high-skilled workers matched to high-skilled jobs, the effect on native student's effort is positive (since the weight given to $\left(\frac{2 k}{w^{T}}-\frac{1}{w_{u}^{p}}\right)$ is likely to be reduced and the weight given to the bigger term $\left(\frac{2 k}{w^{T}}-\frac{1}{\alpha w_{u}^{p}}\right)$ is likely to be increased). If, however, immigrants are all positively selected but unskilled, then selection has to be extremely restrictive in the sense that only immigrants with the highest motivation are admitted for the overall effect on school incentives to be positive. Similarly, a negative selection of only unskilled immigrants will always affect natives negatively, while a negative selection of skilled immigrants has to be extremely negative to have the same effect.

A corollary of the previous point is that the selection of immigrants can have important implications on school segregation. If the selection of immigrants is negative, or even if positive, it involves mainly unskilled workers; this can easily lead to a flight from some schools into others. In many countries, this implies a flight to the private schools sector. Indeed, Betts and Fairlie (2003) find that American-native students fly toward private secondary schools in response to the influx of immigrants into public institutions. Similar results are found by Cascio and Lewis (2012) who show that school districts in California with larger increases in low-English Hispanic enrollment are those which exhibited greater relative reductions in the rate of settlement of non-Hispanic children between 1970 and 2000. Also, Berniell (2010) discussing the massive recent flow of immigrants into Spain shows that, in 1998-1999, when the fraction of immigrants in Madrid was only 2.6\%, about $59 \%$ of natives were attending public schools, while one decade later-when immigrants comprised $17 \%$ of total population roughly $50 \%$ of natives chose public institutions. On the other hand, in 1998-1999 only $68 \%$ of immigrant parents were choosing public schools, while in 2008-2009 this number raised to 77\%. Farre et al. (2011) also discuss this phenomenon for the Spanish case and provide a calibrated model where immigration is indeed the driving force for this sorting.

\section{The effect of immigration on school resources}

In this section, we allow school resources to be endogenous. Let us denote by $r$ the amount of resources an administration gives to a particular school. This could be

\footnotetext{
27 If schools are segregated by the skill level of parents, i.e., children of unskilled workers are schooled together and so are children of skilled workers, or if immigration does not change the classroom composition of children with skilled versus unskilled parents, then the natives always benefit if immigrants have a high parental motivation, and they suffer otherwise.
} 
thought of as class size (or teacher-student ratio) as well as other resources, such as support to teaching staff, computers and other means of making the provision of incentives easier for teachers. More resources reduce the teacher's time cost of providing incentives, which we model by dividing this time cost by the amount of resources $r$. We assume $r$ is the same for all schools, and it is announced by the policy-maker before parents and headmasters decide on the level of incentives taking $r$ as given. Given $r$, the utility of a headmaster is now:

$$
U^{T}=\frac{\theta^{T}}{M} \sum_{i=1}^{M}\left(w_{s}^{c} e_{i}+\left(1-e_{i}\right) w_{u}^{c}\right)+\left(T_{T}-\frac{1}{2 r M} \sum_{i=1}^{M} e_{i} c_{T}\right) w^{T} .
$$

Following the previous analysis, we can obtain the equilibrium values of the key variables of the school system:

Lemma 4 The optimal strength of the incentives set by parents is given by

$$
c_{p_{l}}^{j}=\left(w_{s}^{c}-w_{u}^{c}\right)\left(\psi_{l}^{j}-\frac{2}{3} \frac{r \theta^{T}}{w^{T}}+\frac{M_{I} \overline{\Omega_{I}}+M_{N} \overline{\Omega_{N}}}{3\left(M_{N}+M_{I}\right)}\right) \text { for } j=N, I .
$$

while the optimal school incentives are

$$
c_{T}^{A}=\frac{2}{3}\left(w_{s}^{c}-w_{u}^{c}\right)\left(\frac{2 r \theta^{T}}{w^{T}}-\frac{M_{I} \overline{\Omega_{I}}+M_{N} \overline{\Omega_{N}}}{\left(M_{N}+M_{I}\right)}\right) .
$$

The learning effort of an immigrant child and a native child given by (6) is therefore

$$
e_{i}^{j}=\left(w_{s}^{c}-w_{u}^{c}\right)\left(\psi_{l}^{j}+\frac{2}{3} \frac{r \theta^{T}}{w^{T}}-\frac{M_{I} \overline{\Omega_{I}}+M_{N} \overline{\Omega_{N}}}{3\left(M_{N}+M_{I}\right)}\right) \text { for } j=N, I
$$

\section{Proof See "Appendix 4."}

Now, we introduce the utility of the policy-maker who decides the level of resources for the schools. The policy-maker maximizes the complete utility of the (median voter) parent (denoted by $\bar{P}_{i}$ ) which requires adding the cost of the school resources $(r)$. This median voter is a native (the median of the natives) given that in most countries first-generation immigrants do not get the right of vote, or they get it when they are naturalized at which point most of their children will have already gone (at least partially) through the education system. ${ }^{28}$ The assumption that the resources are decided with the utility of the median voter in mind is a natural one, even if immigration does cause some flight of students into private schools. ${ }^{29}$ The reason is that, in spite of

\footnotetext{
28 To become a US citizen, an immigrant must have been a permanent resident for at least five years. Becoming a permanent resident also takes a few years, and we are considering immigrants who already have children at the time they emigrate.

29 See Betts and Fairlie (2003), Cascio and Lewis (2012) for the evidence of public school flight due to immigration in the US, Berniell (2010) and Farre et al. (2011) for Spain.
} 
the flight, a large majority of students in most countries are educated in public schools, so the median voter typically has a concern for public school funding. ${ }^{30}$ In addition, it is easy to see that the implications we derive below are unchanged qualitatively if the politician makes decisions on resources based on the need of another order statistic of the population, rather than on the median.

The costs of resources $r$ are paid by parents through general taxation, which parents care about, and are internalized by the policy-maker when deciding $r$. Resource costs are assumed to be quadratic. ${ }^{31}$

Thus, we can represent the policy-maker's preferences as,

$$
U_{P M}=U_{P_{M}}-\frac{\rho}{2} r^{2},
$$

where $\rho$ is a constant parameter summarizing the cost of resources. Our formulation assumes that schools are financed out of lump sum taxation and the government keeps a balanced budget.

Substituting (34) and (32) into (35), and then optimizing $U_{P M}$ over $r$, we obtain:

$$
r=\frac{\left(w_{s}^{c}-w_{u}^{c}\right)^{2} \frac{2}{3} \frac{\theta^{T}}{w^{T}}\left(\theta_{i_{M}}+w^{p_{i_{M}}}\left(\frac{M_{I} \overline{\Omega_{I}}+M_{N} \overline{\Omega_{N}}}{3\left(M_{N}+M_{I}\right)}\right)\right)}{\rho-w^{p_{i_{M}}}\left(\left(w_{s}^{c}-w_{u}^{c}\right)^{2}\left(\frac{2}{3} \frac{\theta^{T}}{w^{T}}\right)^{2}\right)}
$$

Note that resources increase in the motivation of the immigrant populations through two sources. First, $r$ is increasing in $\theta^{T}$ which by Assumption 1 depends on the average motivation of the student parents. Secondly, it also depends positively on the parental motivation of immigrants through $\overline{\Omega_{I}}$. Hence, the parental motivation of immigrants reinforces the effects of immigrants selection that happen through $c_{T}$, which we already discussed in Sect. 4. Thus, a poorly selected immigrant population in terms of parental motivation hits the native students (and the more motivated immigrants) directly through school incentives, and indirectly through a reduction in school resources by the policy-makers. ${ }^{32}$

30 As OECD (2015) points out, the data shows that "At least $90 \%$ of all lower secondary students in 35 of the 39 countries with available data attended either public or government-dependent private institutions; and the same percentage was observed among upper secondary students in 31 of the 39 countries with data available. (Table C1.4a)"

31 This can be justified by taking into consideration that the state has monopsony power in the market for teachers and faces a marginal cost function that increases in the number of teachers hired. This is so, for example, because to attract one more teacher the monopsonist has to pay an extra cost, since the marginal potential teacher needs a higher reward to be attracted to the profession.

32 Using Alexopoulos and Cavalcanti (2010), one can reach a contrasting conclusion. In their model, a low-quality education system is associated with cheap domestic services, which are mainly enjoyed by the political and economic elites. In presence of low-skill immigrants, who provide low cost services, the elites would not oppose establishing a public education system to train domestic children. Thus, higher quality of public education may be attributed to the arrival of low-skill immigrants. Notice, however, that this argument would fail if immigrant children go to school, which is exactly the situation studied in our paper. 
Several authors have found evidence that bad immigrant selection leads to a reduction in public spending on schooling (empirical regularity 2). Using a quantitative model of school choice and voting over public education (Coen-Pirani 2015) shows that education spending per student in California would have been 24 percent higher in the year 2000 if US immigration had been restricted to its 1970 level. As in our paper, Coen-Pirani (2015) abstracts from illegal immigration and allows only native households to vote. His calibrated parameters indicate that immigrants in California care relatively less for education than natives, hence our model provides an alternative explanation for his findings. The relationship between resources dedicated to public schools and immigration is also examined by Dottori and Shen (2008). They provide cross-country evidence (e.g., a mean-difference test) that countries that experience negative changes in public expenditure per pupil from 1990 to 2004 Docquier and Marfouk 2006 data set) are those with larger increases in the low-skilled immigrants' share of the population (UNESCO data). This finding is consistent with our model, if low-skilled immigrants are also less concerned about education on average than high-skilled immigrants. Indeed, this negative correlation disappears when (Dottori and Shen 2008) look at changes in the share of immigrants with tertiary education and lagged changes in public expenditure per pupil. As we also discussed in Sect. 4, these effects will be reinforced if, in addition, there is a flight of natives away from public schools into private ones, as Berniell (2010) documents has happened in Spain recently, for example. The calibrated model of Farre et al. (2011) also indicates that immigration in Spain led to a large reduction of about 11 percent in public spending per student. Finally, Speciale (2012) finds this process to be prevalent in Europe.

There is possibly one more channel for immigrants' motivation to impact education. So far, we have assumed that the median voter is the median of the natives, the only ones who can vote. But suppose that immigrants earn the right of vote sufficiently early after arrival to the destination country. Then, poorly selected immigrants would shift the median voter toward an individual who cares less about education and hence lowers the level of resources even further. Obviously, the vicious cycle of selection becomes virtuous in case of positive selection. There is a higher level of $c_{T}$, a higher level of resources $r$ and the immigrant effect may be improved by enfranchising the immigrants.

Another important observation is that our assumption on funding resources implies that immigrants are legal, so they pay taxes. If they are illegal (non-tax paying) but exogenous in number, we would effectively have a higher level of $\rho$, which would entail a lower level of resources. If they were illegal and also their number were endogenous, an increase in resources would bring more of them, and the effect is less easy to compute but similar to having a technology with more rapidly decreasing returns to extra resources.

\section{Concluding discussion}

In this paper, we propose a model of endogenous migration and human capital production that allows us to reproduce the main empirical regularities in the literature which we discuss extensively in light of our theoretical results. We emphasize parental moti- 
vation as a key characteristic to understand the effects of immigration on human capital formation both of immigrant and native children. While some of the regularities could be explained by other models, ${ }^{33}$ the association of children's school performance with parental immigration cost is unique to our analysis. It requires a selection process, which we argue to be likely to be parental motivation and not actual child ability since many migration decisions are taken before child ability is observed. ${ }^{34}$ Our model can explain why students from different origins exhibit so widely different performances in the host country even after controlling for observable characteristics and why students from the same origin country perform better in some host countries than others. Other results of our model are not surprising. We provide conditions under which increased parental motivation also leads to a higher school involvement and show that children's learning efforts increase in parental motivation which trivially delivers empirical regularity 4 that immigrant parents with highly motivated parents tend to perform better at school. These more obvious consequences of parental motivation demonstrate the robustness of our model.

Parental motivation per se is unobservable like intrinsic motivation to which it is closely related. Recently, the economic literature has made huge progresses to measure such variables. For example, Borghans and Schils (2015) have shown that PISA scores can be used to measure non-cognitive abilities of students, such as "agreeableness, and motivational attitudes toward learning" and those studies are predictive of the success of those students later in life. Balart et al. (2015) in fact show that those same abilities, picked up indirectly through PISA test scores, are predictive of national GDP growth. More generally, Heckman and his co-authors (see, e.g., Cunha et al. 2010) have extensively shown that non-cognitive abilities, hitherto thought difficult to measure, ${ }^{35}$ are as important or more as traditional cognitive abilities in determining the human capital of a population. Our model thus provides a challenge to the empirical literature to try to measure parental motivation. The educational literature has already attempted similar things (Bouchard et al. 2007; Katz et al. 2011; Grolnick and Slowiaczek 1994) using questionnaires to capture the motivation for parental involvement. In Grolnick and Slowiaczek (1994), these questionnaires present parents with different parental involvement activities and ask parents how true the following reasons for their involvement in the activity are: external (e.g., because I am supposed to), introjected (e.g., because I would feel guilty if I did not), identified (e.g., because I think it is important) and intrinsic (because it is fun) (Grolnick 2015). Our parental motivation parameter is closest to identified and intrinsic motivation in these studies.

Parental motivation may be correlated with other relevant attributes like work ethic or sociability. Our analysis can be extended to understand the role of families in

\footnotetext{
33 If immigrant children study less, the negative effect of immigrant students on native performance (empirical regularity 1) and the declining in school resources due to an increase in the share of immigrant children (empirical regularity 2) could be both explained by a theory of simple peer effects. If native parents are aware of the negative peer effects of immigrant children, this could lead to a flight to private schools resulting to less political support for public investment.

34 We thank an anonymous referee for pointing this out.

35 McBride (2012) for example says that "non-cognitive traits are qualitative in nature making evaluation more subjective and difficult to measure.
} 
improving assimilation of immigrants and their impact on host societies. It is important to bear in mind that there is no clear correlation between parental motivation and other observable measures of skill intensity like, for example, years of schooling. In this sense, our analysis warns against immigration policies aiming exclusively at attracting immigrants merely on their skills.

Our model can also be used to inform about the effects of different policies in terms of the selection of immigrants in parental motivation. If next generation's human capital is the only concern, our model suggests that the naturalization of immigrant children but not of the parents might be a good idea. Naturalization typically means easier access to better jobs in the future. ${ }^{36}$ If only children are naturalized, these children but not parents their will have a higher wage prospective for high-skill jobs. In terms of our model, this increases the range of parameters for which condition (22) holds and hence favors the selection of highly motivated immigrant parents and leads to better school performance of immigrant children. ${ }^{37}$

The focus of this paper is on the school effects of immigration in the host country. However, applying our model it is straightforward to understand the effect on the educational system in the source country. For example, if immigrants were positively selected and, thus, the most motivated parents leave their countries, this would imply negative effects on their compatriots who stay home. In particular, this can lead to lower school incentives in the source country, and hence to smaller learning efforts of non-emigrant children under plausible conditions. ${ }^{38}$ In fact, Antman (2011) finds evidence of the negative effect of immigration on schooling in the source country. Refocusing the analysis to the home country is an obvious follow-up of this paper.

We restrict our analysis to the effects of immigration on the school system. Clearly, immigration involves effects beyond schools; in the health sector, in the labor market and in many other socially important phenomena. Hence, we do not provide any specific prediction about the optimal policy mix regarding the number of immigrants. Nevertheless, our model uncovers important side and feedback effects, which are generally overlooked in the design and implementation of immigration policy. Notwithstanding the importance of these side effects, a rigorous evaluation of immigration policies requires a model able to capture their general equilibrium implications; an avenue we leave for future research.

Another important extension concerns the interactions between the political economy of the host country and education; immigrants, or at least their children, often

\footnotetext{
36 Bratsberg et al. (2002) provide evidence that in the USA naturalized immigrants have a more favorable job distribution and higher wages than non-naturalized immigrants. Moreover, naturalization leads to further wage growth. It allows entry into certain jobs that are reserved to nationals only, but also gives advantages in terms of signaling long-term commitment and the flexibility to travail. The same results are found by Steinhardt (2008) for Germany and Fourgère and Fougère and Safi (2008) for France.

37 This prediction in consistent with Dronkers and Fleischmann (2010) who study immigration in 13 EU countries and find that a significant macro-characteristic for the educational performance of immigrant children is the destination country's naturalization policy. In particular, the more generous the naturalization policy, the higher the educational attainment of immigrant children.

38 For example, if (29) holds in the home country. The same is also true if (29) fails, but conditions (27) and (28) hold and all emigrants are high-skilled.
} 
eventually achieve political rights ${ }^{39}$ and could importantly, and perhaps unexpectedly, affect political outcomes. ${ }^{40}$

Open Access This article is distributed under the terms of the Creative Commons Attribution 4.0 International License (http://creativecommons.org/licenses/by/4.0/), which permits unrestricted use, distribution, and reproduction in any medium, provided you give appropriate credit to the original author(s) and the source, provide a link to the Creative Commons license, and indicate if changes were made.

\section{Appendix: Proofs}

\section{Appendix 1: Proof of Lemma 1}

Using the notation introduced in (9) and (10), the optimal level of incentives of native and immigrant parents (8) can be written as

$$
\begin{aligned}
& c_{p_{i}}^{N}=\psi_{i}^{N}\left(w_{s}^{c}-w_{u}^{c}\right)-\frac{1}{2}\left(\frac{\theta^{T}}{w^{T}}\left(w_{s}^{c}-w_{u}^{c}\right)-\frac{M_{N} \overline{c_{p}^{N}}+M_{I} \overline{c_{p}^{I}}}{2 M}\right) . \\
& c_{p_{i}}^{I}=\psi_{l}^{I}\left(w_{s}^{c}-w_{u}^{c}\right)-\frac{1}{2}\left(\frac{\theta^{T}}{w^{T}}\left(w_{s}^{c}-w_{u}^{c}\right)-\frac{M_{N} \overline{c_{p}^{N}}+M_{I} \overline{c_{p}^{I}}}{2 M}\right) .
\end{aligned}
$$

The average parental incentives of immigrants and natives can therefore be written as

$$
\begin{aligned}
& \overline{c_{p}^{N}}=\overline{\Omega_{N}}\left(w_{s}^{c}-w_{u}^{c}\right)-\frac{1}{2} \frac{\theta^{T}}{w^{T}}\left(w_{s}^{c}-w_{u}^{c}\right)+\frac{M_{N} \overline{c_{p}^{N}}+M_{I} \overline{c_{p}^{I}}}{4 M} . \\
& \overline{c_{p}^{I}}=\overline{\Omega_{I}}\left(w_{s}^{c}-w_{u}^{c}\right)-\frac{1}{2} \frac{\theta^{T}}{w^{T}}\left(w_{s}^{c}-w_{u}^{c}\right)+\frac{M_{N} \overline{c_{p}^{N}}+M_{I} \overline{c_{p}^{I}}}{4 M} .
\end{aligned}
$$

Notice as well that $\overline{c_{p}^{I}}=\left(\overline{\Omega_{I}}-\overline{\Omega_{N}}\right)\left(w_{s}^{c}-w_{u}^{c}\right)+\overline{c_{p}^{N}}$. Using this and simplifying, $\overline{c_{p}^{N}}$ and $\overline{c_{p}^{I}}$ become:

$$
\begin{aligned}
& \overline{c_{p}^{N}}=\left(w_{s}^{c}-w_{u}^{c}\right)\left(\frac{4 M-M_{I}}{3 M} \overline{\Omega_{N}}+\frac{M_{I}}{3 M} \overline{\Omega_{I}}-\frac{2}{3} \frac{\theta^{T}}{w^{T}}\right) . \\
& \overline{c_{p}^{A}}=\left(w_{s}^{c}-w_{u}^{c}\right)\left(\frac{3 M+M_{I}}{3 M} \overline{\Omega_{I}}+\frac{M-M_{I}}{3 M} \overline{\Omega_{N}}-\frac{2}{3} \frac{\theta^{T}}{w^{T}}\right),
\end{aligned}
$$

\footnotetext{
39 An interesting model analyzing when immigrants get political rights and its consequences is Ortega (2005).

40 See Levy (2005) for an example of the subtle interaction between different types of groups and education provision in a political economy context.
} 
and therefore:

$$
M_{N} \overline{c_{p}^{N}}+M_{I} \overline{c_{p}^{I}}=\frac{2}{3}\left(w_{s}^{c}-w_{u}^{c}\right)\left(2\left(M_{I} \overline{\Omega_{I}}+M_{N} \overline{\Omega_{N}}\right)-\frac{\left(M_{N}+M_{I}\right) \theta^{T}}{w^{T}}\right)
$$

Plugging (42) into (36), (37) and (7), we then get the desired result.

\section{Appendix 2: Proof of Proposition 3}

Let $I_{+}\left(F_{\xi}\right)=\left\{i \in M \mid \xi_{i}=\xi, F_{i}<F_{\xi}\right\}$, and $I_{-}\left(F_{\xi}\right)=\left\{i \in M \mid \xi_{i}=\xi, F_{i} \geq F_{\xi}\right\}$. Denote by $M_{+}\left(F_{\xi}\right)$ the cardinality of $I_{+}\left(F_{\xi}\right)$ and by $M_{-}\left(F_{\xi}\right)$ the cardinality of $I_{-}\left(F_{\xi}\right)$ Then, under a threshold equilibrium, we can write for any vector of thresholds $F=\left(F_{\xi}\right)_{\xi \in \Xi}$,

$$
\overline{\Omega_{I}}(F)=\frac{\sum_{i \in I_{+}}\left(F_{\xi}\right) \frac{\theta_{i}}{w_{i}^{p}}}{\sum_{\xi \in \Xi} M_{+}\left(F_{\xi}\right)}, \overline{\Omega_{H}}(F)=\frac{\sum_{i \in I_{-}}\left(F_{\xi}\right) \frac{\theta_{i}}{w^{p_{i}}}}{\sum_{\xi \in \Xi} M_{-}\left(F_{\xi}\right)} .
$$

Clearly

$$
\overline{\Omega_{A}}(F)=\frac{M_{+}(F) \overline{\Omega_{I}}(F)+M_{N} \overline{\Omega_{N}}}{\left(M_{N}+M_{+}(F)\right)} .
$$

Let for any $i$ with $\xi_{i}=\xi \in \Xi$

$$
\begin{aligned}
G_{\xi}(F) & \equiv \max \left\{0, T\left(w_{A}^{p_{i}}-w_{H}^{p_{i}}\right)+\theta_{i}\left(w_{u_{A}}^{c}-w_{u_{H}}^{c}\right)\right. \\
& +\frac{\theta_{i}^{2}}{2}\left(\frac{\left(w_{s_{A}}^{c}-w_{u_{A}}^{c}\right)^{2}}{w_{A}^{p_{i}}}-\frac{\left(w_{s_{H}}^{c}-w_{u_{H}}^{c}\right)^{2}}{w_{H}^{p_{i}}}\right) \\
& +\theta_{i}\left(\left(w_{s_{A}}^{c}-w_{u_{A}}^{c}\right)^{2}\left(\frac{2}{3} \frac{\theta_{A}^{T}}{w_{A}^{T}}-\frac{\overline{\Omega_{A}}(F)}{3}\right)-\left(w_{s_{H}}^{c}-w_{u_{H}}^{c}\right)^{2}\left(\frac{2}{3} \frac{\theta_{H}^{T}}{w_{H}^{T}}-\frac{\overline{\Omega_{H}}(F)}{3}\right)\right) \\
& \left.+\frac{1}{2}\left(w_{A}^{p_{i}}\left(\frac{2}{3} \frac{\theta_{A}^{T}}{w_{A}^{T}}-\frac{\overline{\Omega_{A}}(F)}{3}\right)^{2}\left(w_{s_{A}}^{c}-w_{u_{A}}^{c}\right)^{2}-w_{H}^{p_{i}}\left(\frac{2}{3} \frac{\theta_{H}^{T}}{w_{H}^{T}}-\frac{\overline{\Omega_{H}}(F)}{3}\right)^{2}\left(w_{s_{H}}^{c}-w_{u_{H}}^{c}\right)^{2}\right)\right\}
\end{aligned}
$$

Under these conditions, existence is guaranteed by a straightforward application of Brouwer's fixed point theorem, since $G($.) is a continuous function and we have defined $F$ to belong to the convex, compact set $[0, A]^{|\Xi|}$ and $G($.$) also maps into$ $[0, A]^{|\Xi|}$ by the assumption that $\mathcal{A}>\max _{\xi_{i} \in \Xi} U_{P_{i}}$. 


\section{Appendix 3: Proof of Proposition 4}

Under the assumption that $\frac{\partial \overline{\Omega_{N A}}}{\partial \theta_{\xi}}=\frac{\partial \overline{\Omega_{H}}}{\partial \theta_{\xi}}=0$ and we only look at individuals within the same skill group, i.e., individuals are homogeneous in wages, we need to calculate the derivative of the left-hand side of (21) with respect to parental motivation and determine its sign. This derivative is given by

$$
\begin{aligned}
& \left(w_{u_{A}}^{c}-w_{u_{H}}^{c}\right) \\
& +\theta_{i}\left(\frac{\left(w_{s_{A}}^{c}-w_{u_{A}}^{c}\right)^{2}}{w_{A}^{p_{i}}}-\frac{\left(w_{s_{H}}^{c}-w_{u_{H}}^{c}\right)^{2}}{w_{H}^{p_{i}}}\right) \\
& +\left(\left(w_{s_{A}}^{c}-w_{u_{A}}^{c}\right)^{2}\left(\frac{2}{3} \frac{\theta_{A}^{T}}{w_{A}^{T}}-\frac{\overline{\Omega_{A}}(F)}{3}\right)-\left(w_{s_{H}}^{c}-w_{u_{H}}^{c}\right)^{2}\left(\frac{2}{3} \frac{\theta_{H}^{T}}{w_{H}^{T}}-\frac{\overline{\Omega_{H}}(F)}{3}\right)\right),
\end{aligned}
$$

Using the link between school and parental motivation, the last line can become

$$
\frac{1}{3}\left(\left(w_{s_{A}}^{c}-w_{u_{A}}^{c}\right)^{2}\left(\frac{2 k_{A}}{w_{A}^{T}} \overline{\theta_{A}}-\overline{\Omega_{A}}\right)-\left(w_{s_{H}}^{c}-w_{u_{H}}^{c}\right)^{2}\left(\frac{2 k_{A}}{w_{A}^{T}} \overline{\theta_{H}}-\overline{\Omega_{H}}\right)\right)
$$

so that the derivative can be rewritten as

$$
\begin{aligned}
& \theta_{i}\left(\frac{\left(w_{s_{A}}^{c}-w_{u_{A}}^{c}\right)^{2}}{w_{A}^{p_{i}}}-\frac{\left(w_{s_{H}}^{c}-w_{u_{H}}^{c}\right)^{2}}{w_{H}^{p_{i}}}\right) \\
& \quad+\left(w_{u_{A}}^{c}-w_{u_{H}}^{c}\right)+\frac{1}{3}\left(\left(w_{s_{A}}^{c}-w_{u_{A}}^{c}\right)^{2}\left(\frac{2 k_{A}}{w_{A}^{T}} \overline{\theta_{A}}-\overline{\Omega_{A}}\right)-\left(w_{s_{H}}^{c}-w_{u_{H}}^{c}\right)^{2}\left(\frac{2 k_{A}}{w_{A}^{T}} \overline{\theta_{H}}-\overline{\Omega_{H}}\right)\right)
\end{aligned}
$$

It is positive if both lines are positive which gives us conditions (22) and (23). If both (22) and (23) are violated, the derivative is negative. If (22) is violated and (23) holds, the derivative is positive for sufficiently small $\theta_{i}$ and negative for sufficiently high $\theta_{i}$. Hence, (21) reaches its maximum for some intermediate value of $\theta_{i}$. Finally, if (22) holds and (23) is violated, the derivative first decreases in $\theta_{i}$ and then increases in $\theta_{i}$. Hence, (21) reaches its minimum for some intermediate value of $\theta_{i}$.

\section{Appendix 4: Proof of Lemma 4}

Using the first order conditions for children's effort decision (6), we get:

$$
\begin{aligned}
U^{T}= & \frac{\theta^{T}}{M}\left(\sum_{k=1}^{M_{N}}\left(\left(w_{s}^{c}-w_{u}^{c}\right)\left(c_{p_{k}}^{N}+c_{T}\right)+w_{u}^{c}\right)+\sum_{l=1}^{M_{I}}\left(\left(w_{s}^{c}-w_{u}^{c}\right)\left(c_{p_{l}}^{I}+c_{T}\right)+w_{u}^{c}\right)\right) \\
& +\left(T-\frac{1}{2 r M} c_{T}\left(\sum_{k=1}^{M_{N}}\left(c_{p_{k}}^{N}+c_{T}\right)+\sum_{l=1}^{M_{I}}\left(c_{p_{l}}^{I}+c_{T}\right)\right)\right) w^{T} .
\end{aligned}
$$




\section{Hence}

$$
\frac{\partial U^{T}}{\partial c_{T}}=\frac{\theta^{T}}{M}\left(\sum_{k=1}^{M_{N}}\left(w_{s}^{c}-w_{u}^{c}\right)+\sum_{l=1}^{M_{I}}\left(w_{s}^{c}-w_{u}^{c}\right)\right)-\left(\frac{1}{2}\left(\sum_{k=1}^{M_{N}} c_{p_{k}}^{N}+\sum_{l=1}^{M_{I}} c_{p_{l}}^{I}\right)+M c_{T}\right) \frac{w^{T}}{M r}=0
$$

So

$$
c_{T}=\frac{r \theta^{T}}{w^{T}}\left(w_{s}^{c}-w_{u}^{c}\right)-\frac{M_{N} \overline{c_{p}^{N}}+M_{I} \overline{c_{p}^{I}}}{2 M},
$$

For parents, the only change now is that school resources cost money which they will have to pay from general taxation, but given the quasi-linearity in income of utility and that taxation is already decided at the time parents choose their effort, the amount of those taxes do not affect the parental effort decision. Hence,

$$
c_{p_{i}}^{j}=\frac{\theta_{i}}{w^{p_{i}}}\left(w_{s}^{c}-w_{u}^{c}\right)-\frac{1}{2} c_{T} \text { for } j=N ; I
$$

Similar calculations as in Lemma 1 yield the desired result.

\section{References}

Alba, R., Sloan, J., Sperling, J.: The integration imperative: the children of low-status immigrants in the schools of wealthy societies. Annu. Rev. Sociol. 37, 395-415 (2011)

Albarracín, J.: Selecting Immigration in Modern Argentina: Economic, Cultural, International and Institutional Factors. Mimeo, University of Florida, New York (2004)

Albornoz, F., Cabrales, A., Hauk, E.: Immigration and the School System, Empirical Evidence. Discussion Paper, University College London (2011)

Albornoz, F., Berlinski, S., Cabrales, A.: Motivation, resources and the organization of the school system. J. Eur. Econ. Assoc. (2017) (forthcoming)

Alexopoulos, J., Cavalcanti, T.V.D.V.: Cheap home goods and persistent inequality. Econ. Theory 45(3), 417-451 (2010)

Algan, Y., Dustmann, C., Glitz, A., Manning, A.: The economic situation of first and second-generation immigrants in France, Germany and the United Kingdom*. Econ. J. 120(542), F4-F30 (2010)

Anghel, B., Cabrales, A.: The determinants of success in primary education in Spain. J. Public Prog. Policy Eval. 2, 22-53 (2014)

Antman, F.: The intergenerational effects of paternal migration on schooling and work: What can we learn from children's time allocations? J. Dev. Econ. 96(2), 200-208 (2011)

Ashton, P.T., Webb, R.B.: Making a Difference: Teachers' Sense of Efficacy and Student Achievement. Longman Publishing Group, London (1986)

Balart, P., Oosterveen, M., Webbink, H.D.: Test Scores, Noncognitive Skills and Economic Growth. Discussion Paper, IZA Discussion Paper (2015)

Bandura, A.: Social Foundations of Thought and Action: A Social Cognitive Theory. Prentice-Hall, Inc, Upper Saddle River (1986)

Bandura, A.: Self-efficacy: the exercise of control. New York, Freeman (1997)

Berniell, L.: Sorting of Students by Cultural Traits: The Effects of Immigration. Mimeo, New York (2010)

Betts, J.: Educational crowding out: do immigrants affect the educational attainment of American minorities? In: Hamermesh, D., Bean, F. (eds.) Help or Hindrance? The Economic Implications of Immigration for African-Americans. Russell Sage Foundation, New York (1998)

Betts, J., Fairlie, R.: Does immigration induce 'native flight' from public schools into private schools? J. Public Econ. 87, 987-1012 (2003)

Bivona, K.N.: Teacher Morale: The Impact of Teaching Experience, Workplace Conditions, and Workload. Discussion Paper, ERIC (2002) 
Borghans, L., Schils, T.: The Leaning Tower of PISA. Discussion Paper, Working Paper. http://www.solejole.org/13260.pdf (2015). Accessed $24 \mathrm{Feb}$

Borjas, G.: Self-selection and the earnings of immigrants. Am. Econ. Rev. 77, 531-553 (1987)

Borjas, G.: The economic analysis of immigration. Handb. Labor Econ. 3, 1697-1760 (1999)

Bouchard, G., Lee, C.M., Asgary, V., Pelletier, L.: Fathers' motivation for involvement with their children: a self-determination theory perspective. Fathering 5(1), 25 (2007)

Bratsberg, B., Ragan, J., Nasir, Z.: The effect of naturalization on wage growth: a panel study of young male immigrants. J. Labor Econ. 20(3), 568-597 (2002)

Brunello, G., Rocco, L.: The Effect of Immigration on the School Performance of Natives: Cross Country Evidence Using PISA Test Scores. IZA DP No. 5479 (2011)

Brunello, G., Rocco, L.: The effect of immigration on the school performance of natives: cross country evidence using PISA test scores. Econ. Educ. Rev. 32, 234-246 (2013)

Card, M.: Is the new immigration really so bad? Econ. J. 115, 300-323 (2005)

Cascio, E.U., Lewis, E.G.: Cracks in the melting pot: immigration, school choice, and segregation. Am. Econ. J. Econ. Policy 4(3), 91-117 (2012)

Coen-Pirani, D.: Immigration and spending on public education: California, 1970-2000. J. Public Econ. 95, 1386-1396 (2015)

Cunha, F., Heckman, J.J., Schennach, S.M.: Estimating the technology of cognitive and noncognitive skill formation. Econometrica 78(3), 883-931 (2010)

Cutright, M.: How wide open is the door to parent involvement in the schools? PTA Today 10(2), 10-11 (1984)

De Fraja, G., Oliveira, T., Zanchi, L.: Must try harder. Evaluating the role of effort on examination results, review of economics and statistics. Rev. Econ. Stat. 92(3), 577-597 (2010)

Docquier, F., Marfouk, A.: International migration by education attainment (1990-2000). In: Ozden, C., Schiff, M. (eds.) International Migration, Remittances and the Brain Drain, Chap. 5. PalgraveMacmillan, Basingstoke (2006)

Doepke, M., Zilibotti, F.: Parenting with Style: Altruism and Paternalism in Intergenerational Preference Transmission. Discussion Paper, National Bureau of Economic Research (2014)

Dottori, D., Shen, I.L.: Low-Skilled Immigration and Education Policy with Endogenous Fertility. Discussion Paper 2008-22. Department of Economics, Université Catholique de Louvain (2008)

Dottori, D., Estevan, F., Shen, I.-L.: Reshaping the schooling system: the role of immigration. J. Econ. Theory 148, 2124-2149 (2013)

Dronkers, J., Fleischmann, F.: The educational attainment of second generation immigrants from different countries of origin in the EU member-states. Qual. Inequal. Educ. 2, 163-204 (2010)

Dustmann, C., Theodoropoulos, N.: Ethnic minority immigrants and their children in Britain. Oxf. Econ. Pap. 62, 209-233 (2010)

Dustmann, C., Frattini, T., Theodoropoulos, N.: Ethnicity and Second Generation Immigrants in Britain. CReAM Discussion Paper No 04/10 (2010)

Dustmann, C., Frattini, T., Lanzara, G.: Educational achievement of second-generation immigrants: an international comparison*. Econ. Policy 27(69), 143-185 (2012)

Fan, X., Chen, M.: Parental involvement and students' academic achievement: a meta-analysis. Educ. Psychol. Rev. 13, 1-22 (2001)

Farre, L., Ortega, F., Tanaka, R.: Immigration, Naturalization and the Future of Public Education. NBER Working Paper 16886 (2011)

Ferreyra, M.M., Liang, P.J.: Information asymmetry and equilibrium monitoring in education. J. Public Econ. 96(1), 237-254 (2012)

Flynn, G.V.: Increasing parental involvement in our schools: the need to overcome obstacles, promote critical behaviors, and provide teacher training. J. Coll. Teach. Learn. 4(2), 23-30 (2011)

Fougère, D., Safi, M.: Naturalization and Employment of Immigrants in France (1968-1999). CEPR Working Paper: DP7092 (2008)

Garcia, D.C.: Exploring connections between the construct of teacher efficacy and family involvement practices implications for urban teacher preparation. Urban Educ. 39(3), 290-315 (2004)

Gasparini, L., Cruces, G., Tornarolli, L.: Recent Trends in Income Inequality in Latin America. Working Papers 132, ECINEQ, Society for the Study of Economic Inequality (2009)

Gibson, S., Dembo, M.H.: Teacher efficacy: a construct validation. J. Educ. Psychol. 76(4), 569 (1984)

Gibson, J., McKenzie, D.: The microeconomic determinants of emigration and return migration of the best and brightest: evidence from the Pacific. J. Dev. Econ. 95(1), 18-29 (2011) 
Glick, J., White, M.: Post-secondary school participation of immigrant and native youth: the role of familial resources and educational expectations. Soc. Sci. Res. 33(2), 272-299 (2004)

Gonzalez-DeHass, A., Willems, P., Holbein, M.: Examining the relationship between parental involvement and student motivation. Educ. Psychol. Rev. 17, 99-123 (2005)

Gould, E., Lavy, V., Paserman, M.: Immigrating to opportunity: estimating the effect of school quality using a natural experiment on Ethiopians in Israel. Q. J. Econ. 119(2), 489-526 (2004)

Gould, E., Lavy, V., Paserman, D.: Does immigration affect the long-term educational outcomes of natives? Quasi-experimental evidence. Econ. J. 119(540), 1243-1269 (2009)

Goyette, K., Xie, Y.: Educational expectations of Asian American youths: determinants and ethnic differences. Sociol. Educ. 72(1), 22-36 (1999)

Grogger, J., Hanson, G.: Income maximization and the selection and sorting of international migrants. J. Dev. Econ. 95, 42-57 (2011)

Grolnick, W.S.: Mothers motivation for involvement in their childrens schooling: mechanisms and outcomes. Motiv. Emot. 39(1), 63-73 (2015)

Grolnick, W., Slowiaczek, M.: Parents' involvement in children's schooling: a multi-dimensional conceptualization and motivational model. Child Dev. 65, 237-252 (1994)

Hao, L., Bonstead-Bruns, M.: Parent-child differences in educational expectations and the academic achievement of immigrant and native students. Sociol. Educ. 71(3), 175-198 (1998)

Heath, A., Rothon, C., Kilpi, E.: The second generation in Western Europe: education, unemployment, and occupational attainment. Annu. Rev. Sociol. 34, 211-235 (2008)

Hoover-Dempsey, K.V., Bassler, O.C., Brissie, J.S.: Parent involvement: contributions of teacher efficacy, school socioeconomic status, and other school characteristics. Am. Educ. Res. J. 24(3), 417-435 (1987)

Hoover-Dempsey, K.V., Battiato, A.C., Walker, J.M., Reed, R.P., DeJong, J.M., Jones, K.P.: Parental involvement in homework. Educ. Psychol. 36(3), 195-209 (2001)

Hoover-Dempsey, K.V., Sandler, H.M.: Why do parents become involved in their children's education?. Rev. Educ. Res. 67(1), 3-42 (1997)

Hoover-Dempsey, K.V., Walker, J.M., Jones, K.P., Reed, R.P.: Teachers involving parents (TIP): results of an in-service teacher education program for enhancing parental involvement. Teach. Teach. Educ. 18(7), 843-867 (2002)

Houtenville, A., Smith Conway, K.: Parental effort, school resources, and student achievement. J. Hum. Resour. 43(2), 437-453 (2008)

Jensen, P., Rasmussen, A.W.: The effect of immigrant concentration in schools on native and immigrant children's reading and math skills. Econ. Educ. Rev. 30(6), 1503-1515 (2011)

Jeynes, W.H.: A meta-analysis of the relation of parental involvement to urban elementary school student academic achievement. Urban Educ. 40, 237-269 (2005)

Jeynes, W.H.: The relationship between parental involvement and urban secondary school student academic achievement: a meta-analysis. Urban Educ. 42, 82-210 (2007)

Kao, G., Thompson, J.: Racial and ethnic stratification in educational achievement and attainment. Annu. Rev. Sociol. 29, 417-442 (2003)

Katz, I., Kaplan, A., Buzukashvily, T.: The role of parents' motivation in students' autonomous motivation for doing homework. Learn. Individ. Differ. 21(4), 376-386 (2011)

Keller, U., Tillman, K.: Post-secondary educational attainment of immigrant and native youth. Soc. Forces 87(1), 121-152 (2008)

Lazar, A., Slostad, F.: How to overcome obstacles to parent-teacher partnerships. Clear. House 72(4), 206-210 (1999)

Levels, M., Dronkers, J.: Educational performance of native and immigrant children from various countries of origin. Ethn. Racial Stud. 31(8), 1404-1425 (2008)

Levels, M., Dronkers, J., Kraaykamp, G.: Immigrant children's educational achievement in western countries: origin, destination, and community effects on mathematical performance. Am. Sociol. Rev. 73, 835-853 (2008)

Levy, G.: The politics of public provision of education. Q. J. Econ. 120, 1507-1534 (2005)

Lumsden, L.: Teacher Morale. ERIC Digest, Number 120. Discussion Paper, ERIC (1998)

Marks, G.: Accounting for immigrant non-immigrant differences in reading and mathematics in twenty countries. Ethn. Racial Stud. 28, 925-946 (2005)

McBride, T.M.: Study of Personnel Attrition and Revocation within US Marine Corps Air Traffic Control Specialties. Discussion Paper, DTIC Document (2012) 
McKenzie, D., Rapoport, H.: Self-selection patterns in Mexico-U.S. migration: the role of migration networks. Rev. Econ. Stat. 92(4), 811-821 (2010)

Moles, O.C.: Synthesis of recent research on parent participation in children's education. Educ. Leadersh. 40(2), 44-47 (1982)

OECD: Education at a Glance 2015: OECD Indicators. OECD Publishing, Paris (2015)

Ohinata, A., van Ours, J.C.: How Immigrant Children Affect the Academic Achievement of Native Dutch Children. CEPR DP 8178 (2011)

Oostdam, R., Hooge, E.: Making the difference with active parenting; forming educational partnerships between parents and schools. Eur. J. Psychol. Educ. 28(2), 337-351 (2013)

Ortega, F.: Immigration quotas and skill upgrading. J. Public Econ. 89, 1841-1863 (2005)

Perie, M., Baker, D.P.: Job Satisfaction Among America's Teachers: Effects of Workplace Conditions, Background Characteristics, and Teacher Compensation. Statistical Analysis Report. Discussion paper, ERIC (1997)

Pop-Eleches, C., Urquiola, M.: Going to a better school: effects and behavioral responses. Am. Econ. Rev. 130(4), 1289-1324 (2013). (Frontiers)

Ross, J.A.: Beliefs That Make a Difference: The Origins and Impacts of Teacher Efficacy. Discussion Paper, ERIC (1994)

Sahin, A.: The Incentive Effects of Tuition Subsidies on Student Effort. Federal Reserve Bank of New York, New York (2004)

Sanders, M.G.: Building family partnerships that last. Educ. Leadersh. 54(3), 61-66 (1996)

Sanders, M.G.: The effects of school, family, and community support on the academic achievement of African American adolescents. Urban Educ. 33, 385-409 (1998)

Schnepf, S.: How Different are Immigrants? A Cross-Country and Cross-Survey Analysis of Educational Achievement. IZA DP No. 1398 (2004)

Speciale, B.: Does inmigration affect public education expenditures? Quasi experimental evidence. J. Public Econ. 96(9-10), 773-783 (2012)

Steinhardt, M.: Does Citizenship Matter? The Economic Impact of Naturalizations in Germany. Development Working Papers 266, Centro Studi Luca dÁgliano, University of Milano (2008)

Stinebrickner, R., Stinebrickner, T.: The causal effect of studying on academic performance. BE J. Econ. Anal. Policy 8(1) (2008) (Frontiers)

Thornton, H.J.: What can we learn about retaining teachers from PDS teachers' voices? Middle Sch. J. 35(4), 5-12 (2004) 